$(200)$
$167 r$
110.595

\title{
On the air-scattering of
} gamma rays from

thick uranium sources

By A. Y. Sakakura

Trace Elements Investigations Report 595

UNITED STATES DEPARTMENT OF THE INTERIOR GEOLOGICAL SURVEY 
Physics

This document consists of 99 pages, Series A

UNITED STATES DEPARTMENT OF THE INTERIOR

GEOLOGICAL SURVEY

ON THE AIR-SCATTERING OF GAMMA RAYS

FROM THICK URANIUM SOURCES

By

Arthur Y。 Sakakura

December 1955

Trace Elements Investigations Report 595

This preliminary report is distributed without editorial and technical review for conformity with official standards and nomenclature. It is not for public inspection or quotation.

This report concerns work done on behalf of the Division of Research of the $U_{0} S_{c}$ Atomic Energy Commission. 


$$
\text { USGS - TEI-595 }
$$

\section{PHYSICS}

Distribution (Series A)

No. of copies

Atomic Energy Commission, Washington .............. 2

Division of Raw Materials, Albuquerque ............. 1

Division of Raw Materials, Austin . . . . . . . . . . 1

Division of Raw Materials, Butte .............. 1

Division of Raw Materials, Casper . . . . . . . . . . 1

Division of Raw Materials, Denver. . . . . . . . . . . 1

Division of Raw Materials, Ishpeming . . . . . . . . . . 1

Division of Raw Materials, Phoenix............. 1

Division of Raw Materials, Rapid City.............. I

Division of Raw Materials, St. George............. I

Division of Raw Materials, Salt Lake City. . . . . . . . . I

Division of Raw Materials, Washington. ............ 3

Division of Research, Washington .............. 1

Exploration Division, Grand Junction Operations Office . ... I

Grand Junction Operations Office .............. 1

Technical Information Extension, Oak Ridge . . . . . . . 6

U. S. Geological Surveys:

Fuels Branch, Washington ................... 1

Geochemistry and Petrology Branch, Washington. . . . . . . . I

Geophysics Branch, Washington. ............. 6

Mineral Deposits Branch, Washington. ............. 1

P. C. Bateman, Menlo Park. ................. 1

A. L. Brokaw, Grand Junction ................ I

N. M. Denson, Denver ................... 1

A. H。Koschmann, Denver. ................ 1

I. R。 Page, Washington ................ 1

Q. D. Singewald, Beltsville................ 1

A. E. Weissenborn, Spokane ............... . I

TEPCO, Denver. .......................... 2

TEPCO, RPS, Washington, (including master) .......... 2 
CONTENTS

Part 1. Gamma-ray intensity from elementary and broad sources

Abstract.000000000000000000000000000000000000000000000000 7

Introduction.0.00000000000000000000000000000,00000000000.0. 8

Acknowledgments 000000000000000000000000000000000010

Determination of empirical relations ................. 11

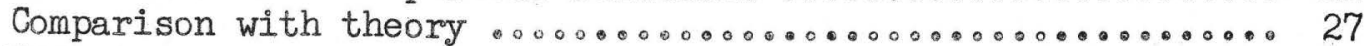

Effect of time constant and the cone of response .......... 42

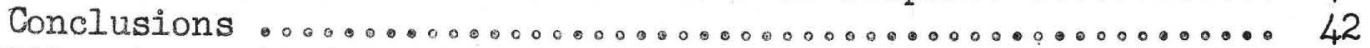

Iiterature cited $\ldots 0000000000000000000000 \ldots 00 \ldots 00000045$

Appendix I 0.0.0000.0.0.0.0000000000000000000000000.47 47

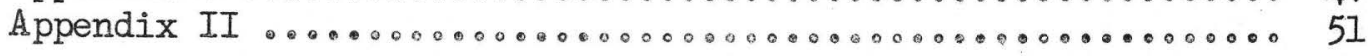

Part 2。 Gamma-ray intensity from idealized sources and interpretation of radioactivity anomalies

Abstract 00000000000000000000000000000000000000000000000055

Introduction .0.

Acknowledgments $00000000000000000000000000000000000 \ldots 059$

Selected idealized sources $000000000000000000 \ldots \ldots \ldots 000059$

Relationship of observable data to source characteristics ... 75

Interpretation of anomalies $000000000000000000 \ldots \ldots \ldots \ldots 0090$

Conclusions 00000000000000000000000000000000000000000009$]$

Literature cited 0000000000000000000000000000000000000095

Appendix I 00000000000000000000000000000000000000000000000 96

Appendix II 00000000000000000000000000000000000000000000000098

\section{ILLUSTRATIONS}

Figure 1. Elementary source geometry 00000000000000000000014

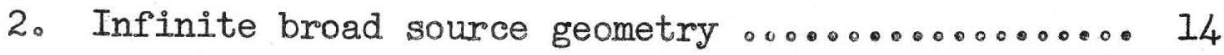

3. Broad source data $00000000000000 \ldots \ldots 0 \ldots \ldots \ldots 17$

4. Elementary source data corrected for angle of view ono

5. Elementary source intensity as function of altitude 00000000000000000000000000000000

6. Relative values of primary, scattered, and total intensities for primary energies of 2.432 and $0.609 \mathrm{Mev}$ from broad source ..0............ 
Figure 7. Computed total and primary fluxes from

Page broad source of uranium emitting

1 photon per $f t^{3}$ per sec.000000000000000000.. 34

8. Decomposition of total flux from broad source, of uranium emitting 1 photon per $\mathrm{ft}^{3}$ per sec. into contributions from various lines of spectrum o. . o. $0.000 \ldots \ldots .38$

9. Relative values of primarys scattered, and total intensities for primary energies of 2.432 and 0.609 Mev from elementary source..

10. Computed total and proimary fluxes from elementary source of uranium emitting

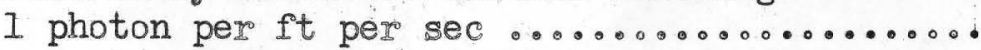

11. Decomposition of total flux from elementary source of uranium emitting 1 photon per ft. per sec. into contributions from various.

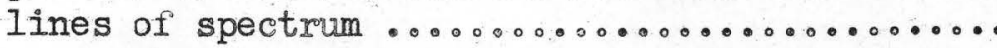

12. Relative intensities at various distances from center of finite sources of various radil

13. Relative intensities at various distances from center line of slab sources of various widths ..

14. Relative intensities at various distances from center line of a slab source $400-\mathrm{ft}$ wide at various angles of approach $\ldots \ldots \ldots \ldots \ldots \ldots \ldots \ldots$

15. Relative intensities at various distances along flight lines at various distances from center of finite sources of $400-\mathrm{ft}$ and $500-\mathrm{ft}$ radii.

16. Ratio of intensity at edge to intensity at center of source

17. Approach of intensity ratios to limiting valuas...

18. Grade necessary to produce 50 counts per second for various radii of finite sources

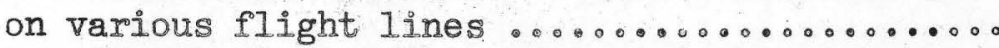

19. Scaled area under curve $G_{4}\left(500, z_{2} a\right)$ vs. scaled peak intensity $G_{3}\left(500, z_{2} a\right)$ of finite sources of various radii (a) 
Page

Figure 20. Ratio of area under curve $\left(\mathrm{H}_{f}\right)$ to peak intensity ( ( $f_{f}$ ) at $\mathrm{z} v \mathrm{~s}_{\text {o }}$ ratio of area under curve ( $\left.\mathrm{H}_{f}\right)$ to peak intensity $\left(\mathrm{I}_{f}\right)$ at 1300-z for finite source of various radii . 080000000000000000000000000000000

21. Ratio of area under curve $\left(\mathrm{H}_{\mathrm{S}}\right)$ to peak intensity ( $I_{S}$ ) vs. width of a slab source at $\varphi=0.00000000000000000000 \ldots \ldots \ldots$.

\section{TABLES}

Table 1. Elementary source data and associated

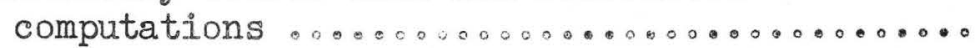

2. Primary ganma rays of uranium series

3. Total flux and total intensities of various components from uranium broad source emitting 1 photon per $\mathrm{ft}^{3}$ per sec .....

4. Primary flux and primary intensities of various components from uranium broad.... ... source emitting 1 photon per $\mathrm{ft}^{3}$ per sec .....

5. Total flux and total intensities of various components from uranium elementary source emitting 1 photon per ft per sec

6. Primary flux and primary intensities of various components from uranium elementary source emitting I photon per ft per sec .......

7. The function $G_{3}(500, P, a) 00000000000 \ldots 062$

8. The function $G_{1}(500, y, a) \ldots \ldots \ldots 0 \ldots \ldots \ldots \ldots \ldots 66$

9. The function $G_{4}\left(500, z_{2} a\right) \ldots 000 \ldots \ldots \ldots \ldots \ldots \ldots \ldots$

10. Ratio of grade-area predicted from point source relation to actual grademarea as function of

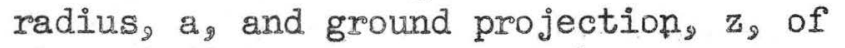
closest distance of approach $\ldots \ldots 00 \ldots \ldots \ldots \ldots$

11. Ratio of point source grademarea to actual grade-area averaged over two flight lines as function of radius, a, and ground projection, $z_{9}$ of closest distance of approach $0000000000000000000 \ldots 000000000$. 
Table 12. Conversion factors to correct point source

Page grade-area prediction to true grade-area for finite sources $\ldots \ldots \ldots \ldots \ldots \ldots \ldots \ldots \ldots \ldots \ldots$

13. Ratio of total counts, $\mathrm{H}_{f}(500, \mathrm{z}, \mathrm{a})$, to peak intensity, $I_{f}\left(500, z_{,} a\right)$, as funtion of radius, $a_{2}$ and ground projection, $z_{2}$ of the closest distance of approach for finite source

14. Ratio of total counts, $\mathrm{H}(500,0, a)$ at normal incidence, to peak intênsity, $I_{\mathbf{S}}(500,0, a)$, as function of width, $a_{\text {, }}$ of a slab source .... 
ON THE A.IR-SCATTERENG OF GAMMA RAYS FROM THICK URANIUM SOURCES

By Arthur Y. Sakakura

PART 1

GAMMA-RAY INTENSITY FROM ELEMENTARY AND BROAD SOURCES

ABSTRACT

Semiquantitative interpretation of data from airborne radioactivity surveying requires detailed knowledge of air-scattered gammaray intensity at considerable air distances from natural, thick-uranium sources. Based on the concept of an elementary source of infinite thickness rather than on the classical point source, semi-empirical expressions are developed for measured gamma-radiation intensities from the two extreme types of natural, thick uranium sources, the elementary (point) and the broad (semi-infinite) source. These expressions agree both with extensive experimental data and with the form and structure of theory.

Theoretical computations based on published solutions of the Boltzmann equation for gamma-ray transport in one medium agree closely with experimental measurements. The calculated value for primary, scattered, and total intensities from thick uranium sources shaw that at considerable air distances the scattered intensities are more than half of the total intensities for energies above $0.4 \mathrm{Mev}$ and become considerably more than half as the lower limit of detector energy response is decreased below $0.4 \mathrm{Mev}$. 


\section{INTRODUCTION}

Airborne radioactivity surveying is now widely and successfully used, primarily to prospect for uranium. In the majority of airborne surveys, the sought-for target is a radioactivity anomaly, a sharp local increase in radiation intensity. Data on anomalies are usually reported on a qualitative basis (Stead, 1955a).

To advance airborne surveying from the qualitative to the semiquantitative estimation of natural source parameters, a greater knowledge of air-scattered gamma-ray intensity at considerable air distances from naturally occurring thick uranium sources is necessary. The scope of the knowledge must be such that for any specific instrument of gamma-ray detection and measurement the various observable data for a given anomaly, such as the peak intensity, the area under the curve, and the shape of the curve, can be correlated with the principal characteristics of a natural source, namely the strength in terms of the equivalent uranium oxide content and the configuration in terms of the surface dimensions.

Inasmuch as naturally occurring sources are usually poorly defined in area and composition, and the radiation effects are obscured by surrounding sources, a purely empirical study would present great difficulties in determining the salient features of the radiation intensity from a given source type. It therefore seems more practicable to investigate numerically and analytically the features of certain simple source types, never found in nature, but nevertheless covering the entire range of variation in shape and size found in natural sources. 
Then, logically, the following sequence of action presents itself:

a. Determination of the radiation intensity, theoreticaliy or experimentally, from an elementary source from which other sources can be constructed.

b. Determination of the radiation intensity from simple sources by distribution of the elementary source over suitable geometrical configurations.

c. Investigation of the relationship between the source characteristics, such as size, grade, shape, and the observable data such as peak intensity reading and area under the counting-rate meter curve for various sources to establish criteria for distinguishing the various source types.

d. With the criteria for distingulshing source types established, relation of source characteristic directly to the observable data without reference to (unknown) distance.

e. Reduction of information gained in the previous steps to a simple "recipe" suitable for actual field applications.

Part I of this paper will be devoted primarily to the establishment of the expression for the elementary source intensity, to a comparison of experimental results with existing theoretical knowledge, and to the effect on the apparent peak intensity of the finite cone of response and resolving time of a counting rate-meter. In Part 2 the characteristics of selected source types is established and a possible mode of interpreting airborne radioactivity measurements in terms of natural source parameters is outlined. 


\section{Acknowledgments}

The writer is deeply grateful to L。 V. Spencer, of the National Bureau of Standards, for a long enlightening discussion on the nature of gamma-ray scattering and on the format.and contents of the paper. The portion entitled "Comparison with Theory" was inserted upon his suggestion. He is also grateful to F. Jo Davis, of Oak Ridge National Laboratory, who took most of the data and to R. H. Ritchie, of Oak Ridge National Laboratory for many fruitful discussions. He is indebted to N. Lazar of Oak Ridge National Laboratory for determining the equilibrium spectrum of $U$.

The work herein reported is part of an investigation carried on by the U. S. Geological Survey on behalf of the Division of Research of the U. S. Atomic Energy Commission. 


\section{DETERMINATION OF EMPIRICAL RETATIONS}

As the fundamental properties of gamma-radiation are well known for the energy range observed in natural sources, the ideal method of interpretation would be based on theoretical computation of the radiation intensity emanating from various sources, by solving the Boltzmann equation for gamma-ray transport in two media. This solution, in general, is a function of three space variables, two angular variables and an energy variable. The advantage of the computational approach is that the results do not have to be resolved in terms of the response characteristics of a particular detector, and that the response of any detector, if its spectral and angular characteristics are known, can be computed. Unfortunately, no satisfactory solutions to the general two-media problems have yet been published, although the U. S. Geological Survey and the Atomic Energy Commission Computing Facility at New York University are now engaged in solving the two-media problems with plane symmetry. However, Fano (1953a, 1953b) and Spencer (1951) have made extensive analytical studies, and a vast quantity of numerical solutions to onemedium problems in plane and spherical geometry exists (Goldstein 1954), from which one may predict trends of solutions in two media. Moreover, for moderate energy gamma rays, two-media problems with plane symmetry can be reduced to equivalent one-medium problems. The general procedure for solving the Boltzmann equation was developed by Spencer and Fano. A topical summary and pertinent bibliography can be found in recent articles by Fano (1953a, 1953b). 
However, the simplest approach is a semi-empirical one, wherein an experimentally determined or assumed form of radiation intensity law for an elementary source is integrated over a suitable geometric configuration to obtain the intensities from various sources. Peirson and Franklin (1951) performed such an integration assuming an inversesquare exponential law which not only neglects the effect of scattering but also the multitudinous lines of the uranium gamma-ray spectrum. Carmichael and others (Steljes, 1952) used the inverse-square law but took air scattering into account by experimentally determining the "effective absorption coefficient" by measuring the radiation from radium sources. Cook (1952) assumed an "effective" energy and utilized "effective" computed cross-section and the inverse-square law. However, there is no a priori reason why any "effective" quantity computed or measured in one source-to-medium orientation should be applicable to others. To avoid this difficulty measurements were made on infinitely thick sources, wherein the integration in depth is already performed in the data, and the various sources are synthesized through integration over a suitable surface.

Although the empirical approach was chosen for. simplicity, it is useful to retain the form and the structure predicted by theory for the purpose of extrapolation into areas not covered by the data. Then, the radiation intensity will take the form of the product of the most penetrating primary component and a buildup factor, a polynomial in the distance variable for the case of moderate penetration (Fano, 1953a; Spencer, 1951). 
There are two extremes in source types found in nature. One of them, which will be called an elementary (point) source, from which every other source can be computed by integration, is depicted in figure $I_{\text {g }}$ an infinite line embedded in the ground. The other extreme, which will be called a broad source, is depicted in figure 2 , a half space uniformly filled with radioactive matter. It is obvious that the second source can be formed by infinite superposition of the former. Thus an empirical form chosen for the elementary source should be such that it not only fits the elementary-source data, but also, when integrated over an infinite area, should fit the broadsource data. In this manner, any intermediate form of sources should be well represented by the integration of the elementary source over a suitable geometrical configuration.

In this section, empirical formulas will be established for the elementary and the broad sources. It is known that the radiation intensity can be written as a product of two factors, one representing the primary contribution from the unscattered components, and the other, a buildup factor representing the contribution from scattered radiation (Fano, 1953a, 1953b; Spencer, 1951). The latter factor is generally a polynomial for moderate penetration.

An extensive series of experimental measurements to provide statistically sound data bearing an absorption and scattering of gamma radiation was planned and completed in cooperation with the Health Physics Division of the Oak Ridge National Laboratory. Measurements were made at various distances above a simulated elementary point source and an infinite broad source with scintillation detection equipment designed and constructed by Oak Ridge National Laboratory and installed in a U. S. Geological Survey multi-engine airplane。 


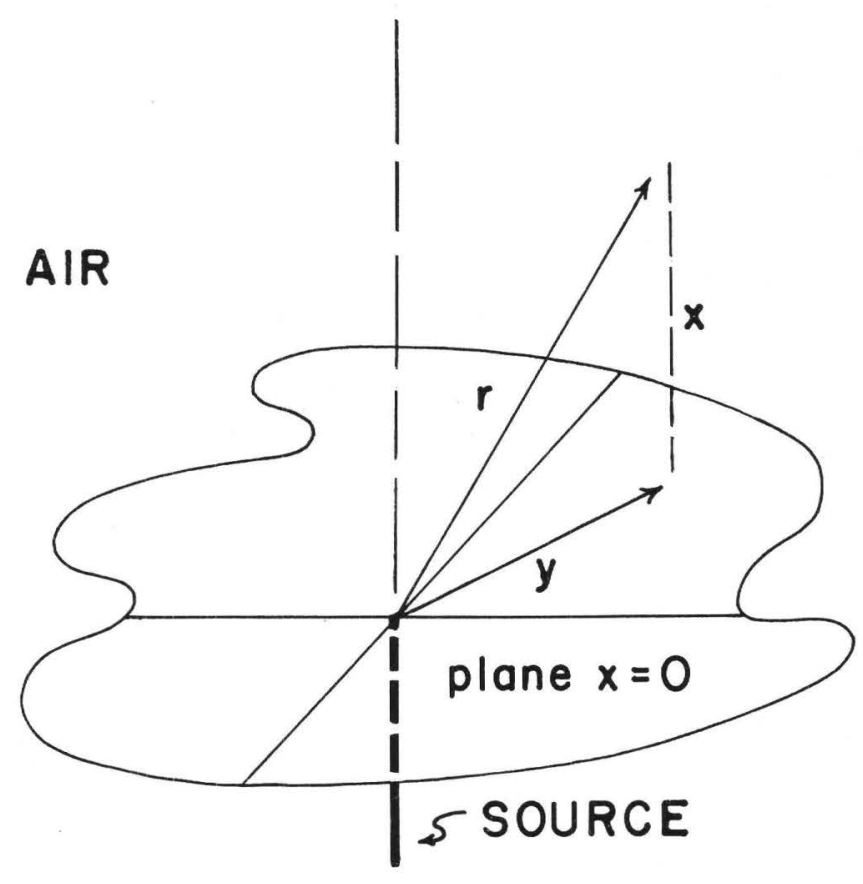

Fig. I. Elementary point source geometry

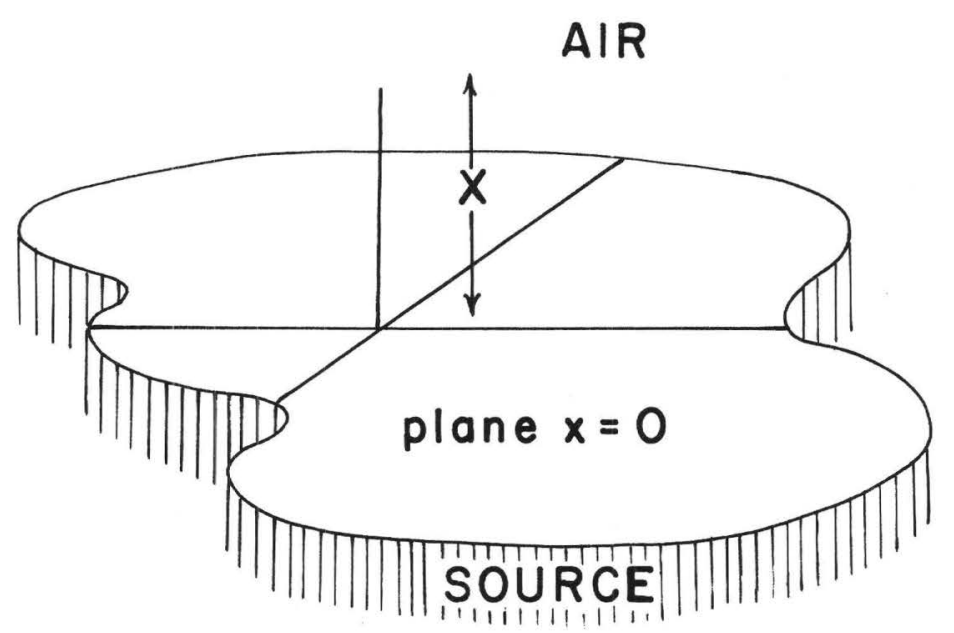

Fig. 2. Infinite broad source geometry 
The simulated elementary source is at Walker Airport, Grand Junction, Colorado, and consists of a slab of carnotite ore 40 feet square and 6 inches thick sealed by a thin rubberized fabric to minimize escape of radon. The source contains 48 tons of ore at 0.35 percent $\mathrm{U}_{3} \mathrm{O}_{8}\left(1.31 \times 10^{3} \mathrm{gU}\right.$ and $\left.47.1 \mathrm{mg} \mathrm{Ra}\right)$.

In comparison with the infinitely thick source, the 6-inch thickness of ore yields 95 percent of the primary intensity of the most abundant gamma ray $(0.609 \mathrm{Mev})$ and 75 percent of the intensity of the most penetrating gamma ray $(2.432 \mathrm{Mev})$. The areal extent of the simulated source is small enough to be considered a point source at air distances several times greater than the effective diameter of the slab.

The experimental measurements over the source were made at 100foot intervals from 100 to 800 feet above the ground both directly over the source and at horizontal distances from the center line to one side of the source, of $125,250,375$, and 500 feet. The flight level of the aircraft was determined by a continuously recording radio altimeter. Flight-line markers for pilot guidance were set up across and parallel to the source with one line of grid markers through the source and perpendicular to the flight-line markers. A gyrostabilized continuous-stripfilm camera recorded each flight so that, from the known focal length of the lens and the distance from the ground and also the horizontal distance offside from the source could be calculated within about 10 feet. The nominal flight levels as determined by the radio altimeter were often in error by as much as 80 feet when compared to the more accurate determinations of position based on the continuous-strip photograph. 
In figure 3 the net counting rates from a broad source at minimum pulse height acceptance levels corresponding to $0.05,0.1,0.2$ and $0.4 \mathrm{Mev}$ are plotted against altitude above the source. Each point corresponds to the average of five readings taken by three observers. The solid lines correspond to exponential curves fitted by least squares. The slopes are constant, and consequently it is concluded that within the limits of experimental error, the spectral composition does not change Consequently, all further measurements and considerations are based on the highest counting rate, corresponding to the lower energy aeceptance level of $0.05 \mathrm{Mev}$.

The broad source is near Fruita, Colorado, an area of Mancos shale several square miles in extent and of essentially uniform composition. Representative trench samples of the shale contained 1.6 percent $K_{\text {, }}$ 0.0017 percent $U$ (fluorimetric), and 0.0013 percent equivalent U. Experimental measurements over the source were made at 100-foot intervals from 100 to 1,000 feet above the ground. 


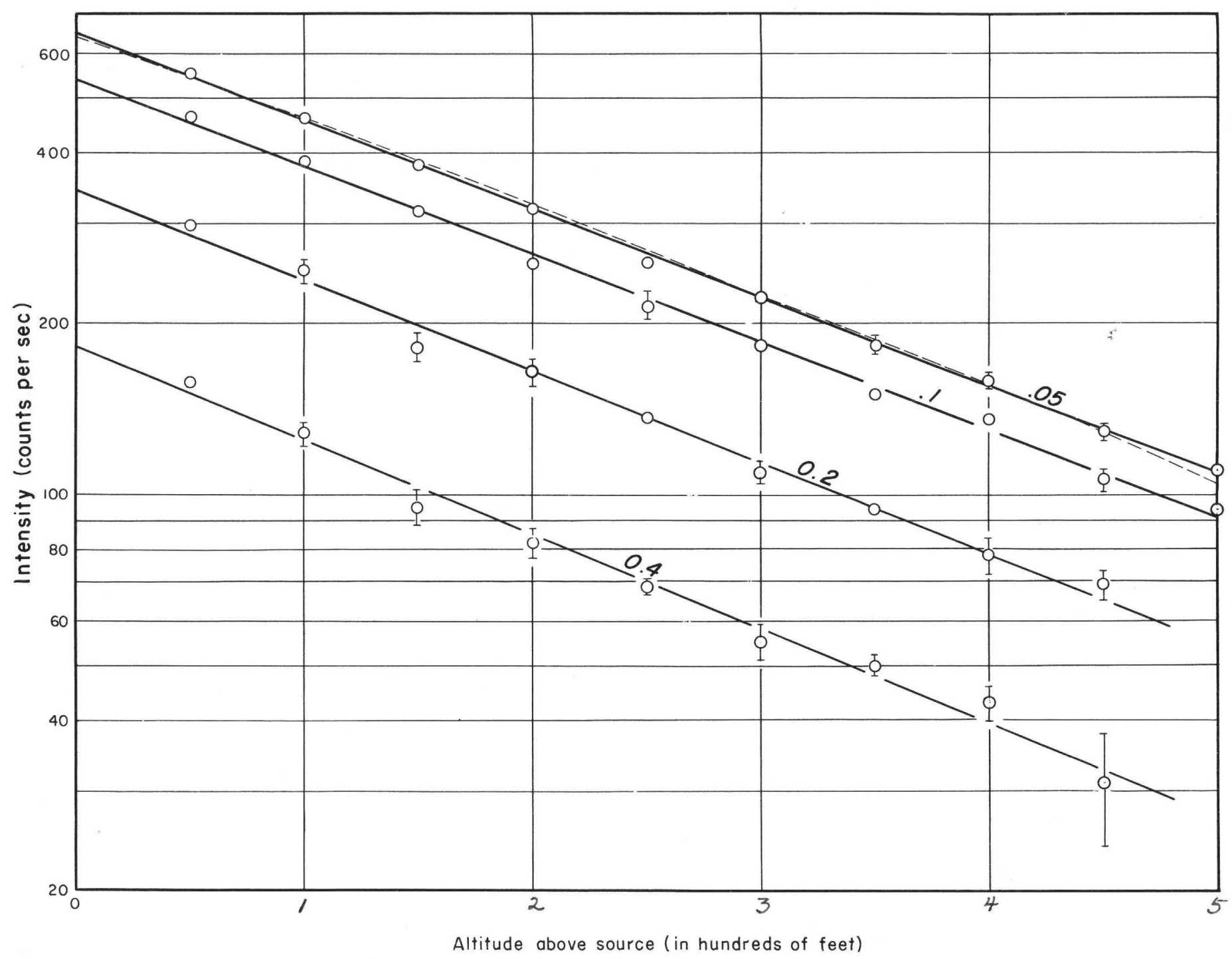

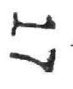

FIGURE 3-BROAD SOURCE DATA.NUMBERS ON CURVES DENOTE ENERGY IN MEV CORRESPONDING TO PULSE HEIGHT ACCEPTANCE LEVELS. SOLID LINES REPRESENT LEAST-SQUARE-FITTED EXPONENTIALS. BROKEN LINE REPRESEITS EXPRESSION (5) OF TEXT. 
The elementary source intensity, $I p$, is expressed as

$$
I p(x, \rho)=\frac{G S A}{S A} \frac{x}{D_{0}} \frac{e^{-\mu_{0} r}}{r^{2}}\left[1+a_{1}\left(\mu_{0} r\right)+a_{2}\left(\mu_{0} r\right)^{2}\right]
$$

where

$$
\begin{aligned}
\mathrm{x}= & \text { altitude of detector above source plane } \\
\rho= & \text { projection on the source plane of the air distance } \\
& \text { from source to detector } \\
\mathrm{r}= & \text { air distance }=\sqrt{\mathrm{x}^{2}+\rho^{2}} \\
\mathrm{C}_{\mathrm{a}} \mathrm{a}_{2} \mathrm{a}_{2}= & \text { constants to be determined } \\
\mathrm{A}= & \text { area of an elementary source } \\
A_{0}= & \text { area of standard elementary source }=1600 \mathrm{ft}^{2} \\
\mathrm{~S}= & \text { grade in eU of source } \\
\mathrm{S}_{0}= & \text { grade in eU of standard source }=0.35 \text { percent } \mathrm{U} \\
\mu_{0}= & \text { Linear absorption coefficient of the most penetrating } \\
& \text { gamma ray of the } U \text { spectrum } \\
= & 1.46 \mathrm{x} 10^{-3} \text { ft at sea level }
\end{aligned}
$$


The factor $x / r$ is the effective area of the source as "seen" by the detector (fig。 I). Because of the strongly absorbing nature of ground, only the gammer rays from a finite depth of an infinitely thick source contribute appreciably to the counting rate. The next factor, $\frac{e^{-\mu_{0}} r}{r^{2}}$, is the primary intensity from the most penetrating component. The square bracketed factor is the buildup factor which is not identical to the buildup factor of theory, as it also includes the effects of more rapidly decaying exponentials of the less penetrating primary components.

The intensity from a broad source, $I_{b}(x)$, is

$$
\begin{aligned}
I_{b}(x) & =2 \pi \int_{0}^{\infty} \frac{I_{p}\left(x_{9} \rho\right) d \rho}{A} \\
& =\frac{2 \pi C S}{S_{0} A}\left\{\left[1+a_{2} \mu_{0} x\right] e^{-\mu_{0} x}+\left(1-a_{1}\right) \mu_{0} x \int_{x}^{\infty} e^{-\mu_{0} r} d r\right\}
\end{aligned}
$$

As these expressions are largely arbitrary, and for the sake of retaining simple expressions, $a_{1}$ is taken to be 1 . Thus

$$
\begin{aligned}
& I_{p}(x, \rho)=\frac{C S A}{S_{0} A_{0}} \frac{x}{r} \frac{e}{r}^{-\mu_{0} r}\left[1+\mu_{0} r+a_{2}\left(\mu_{0} r\right)^{2}\right] \\
& I_{b}(x)=\frac{2 \pi C S}{S_{0} A_{0}} e^{-\mu_{0} x}\left[1+a_{2}\left(\mu_{0} x\right)\right]
\end{aligned}
$$

These, then, are the expressions to be fitted to the data. 
Simple exponential expressions for an elementary source such as those given in Peirson (1951), will, of course, yield simple exponential broad source equations upon integration. Whereas the broad source expressions can be fitted to the data, the simple point source exponential can not be made to approximate with sufficient accuracy the elementary source data. Therefore, either equations (3) or (4) could be used. However, as these formulas represent intensities due to extremes in the geometrical configuration of the source rock, the intensity due to an arbitrary source would best be obtained by considering both equations (3) and (4). The dotted line curve represents the least square fitted expression,

$$
I_{b}(x)=\left(638-218 \mu_{0} x\right) e^{-\mu_{0} x}
$$

from which is obtained the value, -0.342 for $a_{2}$. With $a_{2}$ established, it remains merely to determine $C$. In figure $4 \mathrm{~g}$ the data for the point source, corrected by the factor $\frac{r_{x}}{\mathrm{X}}$ are plotted against air distance $r$. Expression (3) was fitted to all data taken more than 450 feet from the source because the time constant correction is small and this is the region of greatest concern to this particular method of aerial surveying. In Table 1, column 1 gives the air distance in feet, column 2 gives the altitude in feet, column 3 gives the experimental counting rate, column 4 gives the counting rate multiplied by $\frac{r_{x}}{x}$ column 5 gives the data of column 4 divided by $\frac{e}{r^{2}}-\mu_{0}^{r}\left[1+\mu_{0} r-0.342\left(\mu_{0} r\right)^{2}\right]$ yielding $c$, and column 6 gives the averages of column 5 with the nominal altitude and distance of the measurements off-side. 


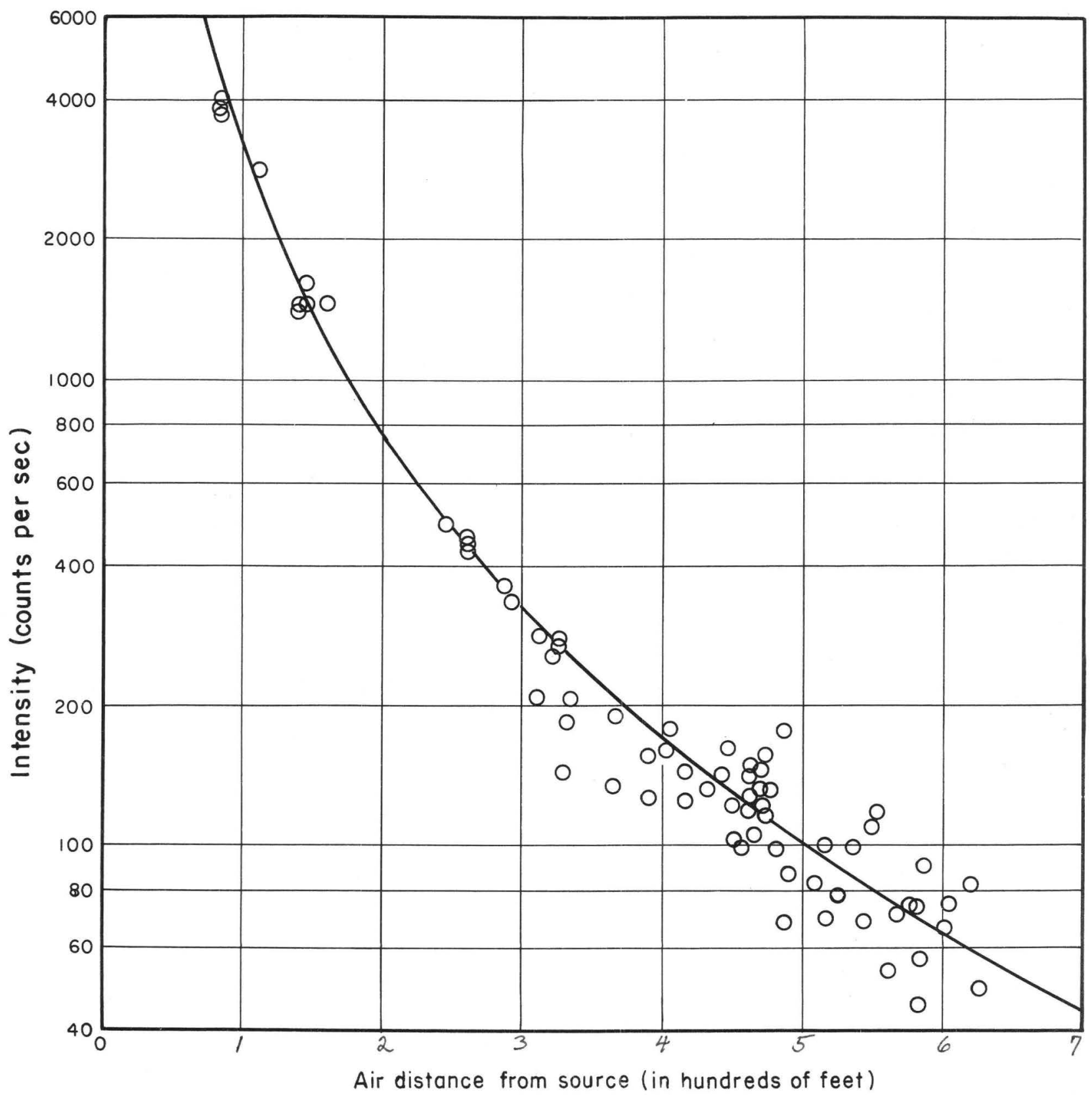

FIGURE 4-ELEMENTARY SOURCE DATA CORRECTED FOR ANGLE OF VIEW. THE CURVE IS EXPRESSION (6) MULTIPLIED BY $r / x$ 
Table 1. Elementary source data and associated computations

\begin{tabular}{|c|c|c|c|c|c|}
\hline $\begin{array}{l}\text { Air } \\
\text { Distance } \\
\text { r(ft) }\end{array}$ & $\begin{array}{l}\text { Altitude } \\
x(f t)\end{array}$ & $\begin{array}{l}\text { Experimental } \\
\text { Intensity (counts } \\
\text { per second) }\end{array}$ & $\begin{array}{l}\text { Experimental } \\
\text { Intensity }\left(\frac{r}{*}\right)\end{array}$ & $\mathrm{C}$ & $\mathrm{C}$ (average) \\
\hline & & \multicolumn{4}{|c|}{$600 \mathrm{ft}$ nominal altitude, $375 \mathrm{ft}$ offside } \\
\hline $\begin{array}{l}560 \\
626 \\
583 \\
601.3\end{array}$ & $\begin{array}{l}470 \\
530 \\
510 \\
520\end{array}$ & $\begin{array}{l}45 \pm 5 \\
42.5 \pm 2.5 \\
40 \\
57.5 \pm 12.5\end{array}$ & $\begin{array}{l}53.6 \pm 6.0 \\
50.2 \pm 3.0 \\
45.8 \\
66.5 \pm 14.5\end{array}$ & $\begin{array}{l}2.21 \times \\
2.74 \\
2.09 \\
3.27\end{array}$ & $(2.57 \pm 0.42) \times 10^{7}$ \\
\hline
\end{tabular}

$500 \mathrm{ft}$ nominal altitude, $375 \mathrm{ft}$ offside

\begin{tabular}{|c|c|c|c|c|c|}
\hline $\begin{array}{l}526 \\
605 \\
566 \\
552 \\
581\end{array}$ & $\begin{array}{l}405 \\
440 \\
440 \\
420 \\
455\end{array}$ & $\begin{array}{l}60 \\
55 \pm 5 \\
55 \pm 5 \\
90 \pm \\
45 \pm 5\end{array}$ & $\begin{array}{l}77.9 \\
75.6 \pm 6.9 \\
70.8 \pm 6.4 \\
118 . \\
57.4 \pm 6.4\end{array}$ & $\begin{array}{l}2.748 \\
3.768 \\
2.996 \\
4.696 \\
2.584\end{array}$ & $(3.36 \pm 0.70) \times 10^{7}$ \\
\hline \multicolumn{6}{|c|}{$400 \mathrm{ft}$ nominal altitude, $375 \mathrm{ft}$ offside } \\
\hline $\begin{array}{l}485 \\
462 \\
480 \\
455 \\
471\end{array}$ & $\begin{array}{l}315 \\
300 \\
315 \\
320 \\
285\end{array}$ & $\begin{array}{l}45 \pm 5 \\
82.5 \pm 2.5 \\
65 \pm 5 \\
70 \pm \\
87.5 \pm 2.5\end{array}$ & $\begin{array}{l}69.3 \pm 7.7 \\
127 . \pm 4 \\
99 . \pm 7.6 \\
99.6 \\
145 . \pm 4\end{array}$ & & \\
\hline \multicolumn{6}{|c|}{$600 \mathrm{ft}$ nominal altitude, $250 \mathrm{ft}$ offside } \\
\hline $\begin{array}{l}580 \\
622 \\
619 \\
577 \\
586\end{array}$ & $\begin{array}{l}540 \\
570 \\
580 \\
520 \\
530\end{array}$ & $\begin{array}{l}70 \pm 10 \\
30 \pm \\
77.5 \pm 7.5 \\
67.5 \pm 2.5 \\
82.5 \pm 2.5\end{array}$ & $\begin{array}{l}75.2 \\
32.8 \\
82.6 \pm 10.6 \\
74.9 \pm 2.8 \\
91.2 \pm 2.8\end{array}$ & $\begin{array}{l}3.38 \\
1.76 \\
4.35 \\
3.32 \\
4.20\end{array}$ & $(3.40 \pm 0.70) \times 10^{7}$ \\
\hline \multicolumn{6}{|c|}{$500 \mathrm{ft}$ nominal altitude, $250 \mathrm{ft}$ offside } \\
\hline $\begin{array}{l}543 \\
485 \\
516 \\
472 \\
465\end{array}$ & $\begin{array}{l}490 \\
425 \\
480 \\
415 \\
415\end{array}$ & $\begin{array}{l}62.5 \pm 2.5 \\
60 \\
65 \pm 5 \\
103 \pm 3 \\
95 \pm 5\end{array}$ & $\begin{array}{l}69.3 \pm 2.8 \\
68.4 \pm \\
69.8 \pm 5.4 \\
117 . \pm 3 \\
106 . \pm 6\end{array}$ & $\begin{array}{l}2.650 \\
1.987 \\
2.34 \\
3.18 \\
2.80\end{array}$ & $(2.59+0.34) \times 10^{7}$ \\
\hline
\end{tabular}


Table 1. Elementary source data and associated computations

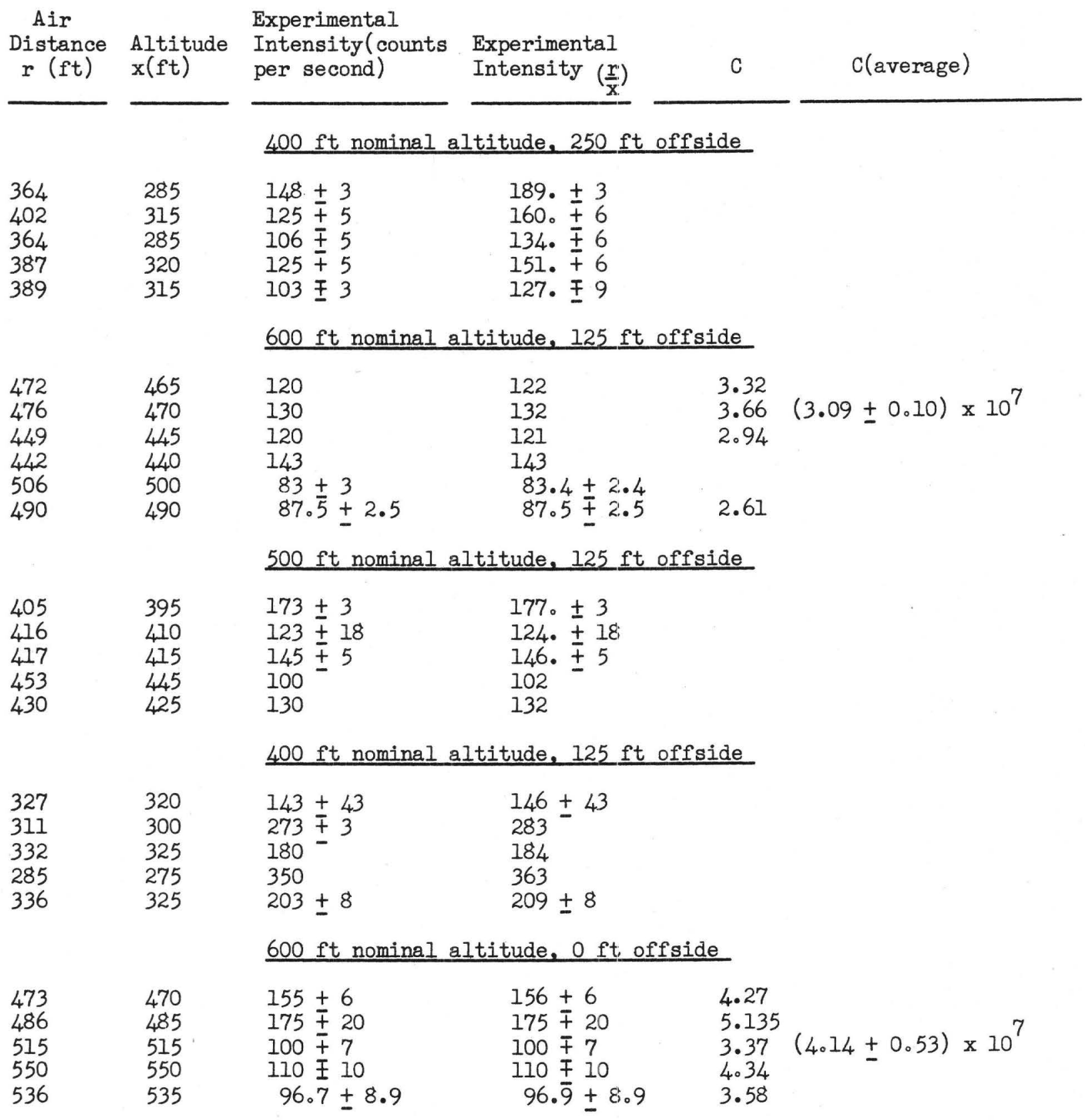


Table 1. Elementary source data and associated computations

Air

Distance

$r(f t)$

Experimental

Altitude Intensity(counts Experimental $x(f t)$

per second)

Intensity $\left(\frac{r}{x}\right)$

C C(average)

$500 \mathrm{ft}$ nominal altitude, $0 \mathrm{ft}$ offside

$\begin{array}{llll}470 & 470 & 133 \pm 9 & 133 \pm 9 \\ 461 & 460 & 140 \pm 7 & 140 \pm 7 \\ 460 & 460 & 148 \pm 2 & 148 \pm 2 \\ 460 & 460 & 118 \pm 8 & 118 \pm 8 \\ 446 & 445 & 163 \pm 2 & 164 \pm 2 \\ & & 400 \text { ft nominal altitude, Oft offside }\end{array}$

$272 \pm 6$

$310+7$

$282 \mp 6$

$255 \mp 3$

$332 \mp 8$

$272 \pm 6$

$310 \pm 7$

$282 \mp 6$

$255+3$

$332 \pm 8$

$300 \mathrm{ft}$ nominal altitude, $0 \mathrm{ft}$ offside

260

260

260

260

245

260

260

260

260

245

$427 \pm 6$

$437 \pm 6$

$433+10$

$460 \mp 7$

$490 \mp 7$

$427 \pm 6$

$437 \pm 6$

$433 \pm 10$

$460 \pm 7$

$491 \pm 7$

$200 \mathrm{ft}$ nominal altitude, $0 \mathrm{ft}$ off side

140

140

160

145

145

111

86

87

85

85
140

140

160

145

145

1400

1480

1350

1620

1550

1400

1480

1350

1620

1550

$100 \mathrm{ft}$ nominal altitude, 0 ft offside

$2810 \pm 260$

$3930 \pm 10$

3650

4000

$3940 \pm 10$

$2840 \pm 260$

$3990 \pm 10$

3730

4020

$3960 \pm 10$ 
The average values of $\mathrm{C}$ (table 1 , columr-6) are grouped so that any systematic deviation will point out an error made in the assumption of the expression (3) for the elementary source intensity. Within experimental error, the $\mathrm{C}^{\text {'S }}$ so obtained are equal. The observational error is calculated as the absolute mean deviation from the mean of data read by three observers from the same charts.

Using the values established for $\mathrm{C}$ and $\mathrm{a}_{2}$, the expressions (3), (4) become

$$
\begin{gathered}
I_{p}(x, \rho)=3.19 \times 10^{7} \frac{\mathrm{SA}}{S_{0} A_{0}} \frac{(x)}{r_{0}} \frac{e^{-\mu_{0} r}}{r^{2}}\left[1+\mu_{0} r-0.342\left(\mu_{0} x\right)^{2}\right] \\
I_{b}(x)=3.19 \times 10^{7} 2 \pi S e^{-\mu_{0} x}\left(1-0.342 \mu_{0} x\right)
\end{gathered}
$$

In figure 42 expression (6) at the point $r=x$ (directly overhead) is compared to experimental data corrected for the angle of view. The fit of the experimental data to the plot of expression (6) is particularly good for air distances less than 450 feet.

In figure 5, the intensity at various altitudes above an elementary source, calculated from expression (6), is plotted for flight lines directly over and at 125, 250, and 500 feet to the side of the source. It is clear that the maximum intensity increases with altitude as the distance of nearest approach to the flight lines is increased.

The accuracy of expression (7) in predicting the equivalent uranium content of broad sources can be determined by comparing it with the experimental expression (5) from which it follows that

$$
3.19 \times 10^{7} \frac{2 \pi S}{S_{0} A_{0}}=638 \text {, or } S=0.0018 \text { percent } \mathrm{eU}_{3} \mathrm{O}_{8}
$$

The predicted value of 0.0018 percent equivalent $\mathrm{U}_{3} \mathrm{O}_{8}$. is considered a satisfactory fit with the analytical value of 0.0013 percent equivalent $\mathrm{U}_{3} \mathrm{O}_{8}$ for a large representative sample of the broad source. 


\section{6}

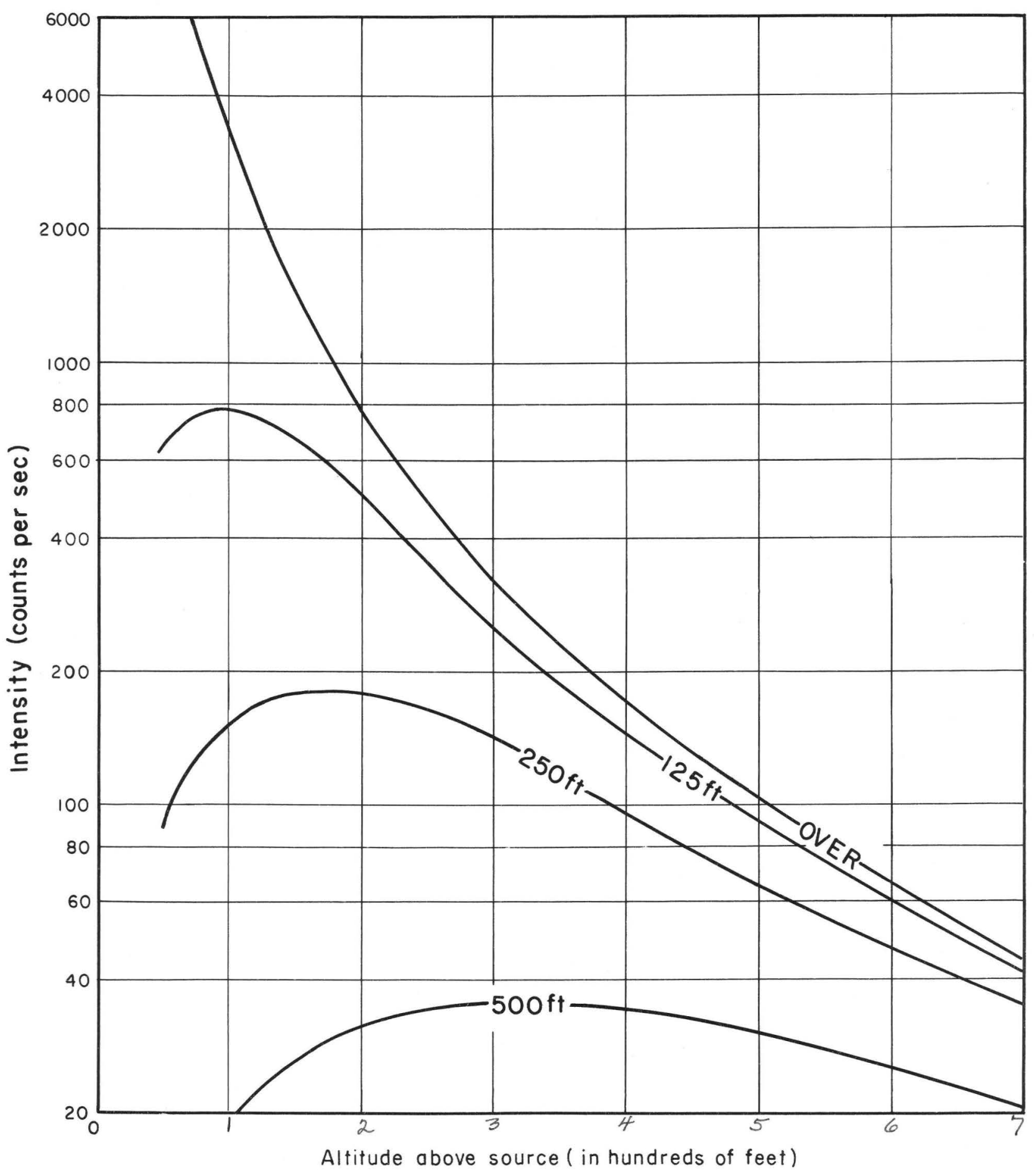

FIGURE 5 ELEMENTARY SOURCE INTENSITY AS FUNCTION OF ALTITUDE. NUMBER ON CURVES DENOTE DISTANCES OFFSIDE 


\section{COMPARISON WITH THEORY}

From existing computations of solutions to the Boltzmann equation in one medium and the knowledge of the primary spectrum of the uranium series, the expected integrated intensity from $0.4 \mathrm{Mev}$ to $2.432 \mathrm{Mev}$ was computed for the broad and elementary source of unit strength, that is, one photon per cubic foot per second and one photon per foot per second. The latter corresponds to a source one square foot in area emitting one photon per cubic foot per second. The details of the calculation are in Appendix I.

For the purpose of this section, the following nomenclature is adopted:

Primary intensity: Number flux due to unscattered photons from one line of the uranium series.

Total intensity: Number flux originating from a given line of the uranium series and including all energies degraded from that line down to $0.4 \mathrm{Mev}$, and including the unscattered flux. This is the response of a non-energy-dependent detector per square foot of detector area.

Primary flux: Superposition of all the primary intensities of the uranium spectrum above $0.4 \mathrm{Mev}$ energy in proper proportion and normalized to unit source strength. 
Total flux: Superposition of all the total intensities. This is the response of a non-energy-dependent detector with a lower energy acceptance at $0.4 \mathrm{Mev}$. The cutoff has been chosen at $0.4 \mathrm{Mev}$ as the spectrum of the uranium series is unambiguously known down to $0.34 \mathrm{Mev}$ (8) and as the Compton effect predominates in this range so that published one-medium computation can be adapted to two media.

Table 2 constructed from the work of Mladjenovic (1954a, 1954b) and confirmed by Lazar (written communication, 1955) gives the energy of the gamma rays above $0.34 \mathrm{Mev}$ and their fractional abundances. These are the values used in computing the individual intensities and the fluxes. The details of the computation are in Appendix I. Tables 3 and 4 contain the computed total and primary intensities and fluxes which are normalized to a broad source emitting 1 photon per $\mathrm{ft}^{3}$ per sec and are plotted in figures 6,7 , and 8 .

In figure 6 the primary, scattered, and total intensities are plotted to an arbitrary scale for initial energies of 0.609 and $2.432 \mathrm{Mev}$, the two extremes in energy found in the spectrum. The importance of the scattered components, particularly for deeper penetrations, can be readily seen from the graph. The futility of any analysis in which scattering is neglected is obvious. 
Table 2. Primary gamma rays of uranium series

\begin{tabular}{|l|l|}
\hline Energy (Mev) & Abundance \\
\hline 0.609 & 0.268 \\
0.769 & 0.0579 \\
0.934 & 0.0282 \\
1.120 & 0.204 \\
1.238 & 0.0741 \\
1.378 & 0.0869 \\
1.509 & 0.0292 \\
1.764 & 0.164 \\
1.848 & 0.0172 \\
2.204 & 0.0522 \\
2.432 & 0.0188 \\
& \\
\hline
\end{tabular}


TABLE 3. TOTAL FLUX AND TOTAL INTENSITIES OF VARIOUS COMPONENTS FROM URANIUM BROAD SOURCE EMITTING I PHOTON PER FT ${ }^{3}$ PER SEC

\begin{tabular}{|c|c|c|c|c|c|c|c|c|c|c|c|c|}
\hline \multirow{4}{*}{$\begin{array}{c}\text { ALTITUDE } \\
\text { (FT) }\end{array}$} & \multicolumn{11}{|c|}{ ENERGY（MEV） } & $\begin{array}{l}\text { TOTAL FLUX } \\
\text { (PHOTONS PER } \\
\text { FT }^{3} \text { PER SEC) }\end{array}$ \\
\hline & 0.609 & 0.769 & 0.934 & 1.120 & 1.238 & 1.378 & 1.509 & 1.764 & 1.843 & 2.204 & 2.432 & \\
\hline & \multicolumn{12}{|c|}{ TOTAL INTENSITY (PHOTONS PER FT² PER SEC) } \\
\hline & 0.0362 & 0.00967 & 0.00561 & 0.0469 & 0.0182 & 0.0226 & 0.00809 & 0.0497 & 0.00531 & 0.0183 & 0.00692 & 0.228 \\
\hline 100 & 0.0222 & 0.00643 & 0.00389 & 0.0337 & 0.0131 & 0.0166 & 0.00607 & 0.0377 & 0.00406 & 0.0441 & 0.00545 & 0.163 \\
\hline 200 & 0.0155 & 0.00469 & 0.00293 & 0.0263 & 0.0104 & 0.0134 & 0.00482 & 0.0308 & 0.00341 & 0.0117 & 0.00455 & 0.130 \\
\hline 300 & 0.0133 & 0.00357 & 0.00237 & 0.0212 & 0.00830 & 0.0108 & 0.00397 & 0.0256 & 0.00277 & 0.00987 & 0.00385 & 0.106 \\
\hline 400 & 0.00831 & 0.00273 & 0.00188 & 0.0170 & 0.00678 & 0.00893 & 0.00327 & 0.0215 & 0.00230 & 0.00840 & 0.00329 & 0.0844 \\
\hline 500 & 0.00624 & 0.00212 & 0.00151 & 0.0138 & 0.00552 & 0.00741 & 0.00270 & 0.0182 & 0.00198 & 0.00720 & 0.00284 & 0.0695 \\
\hline 600 & 0.00472 & 0.00169 & 0.00122 & 0.0113 & 0.00459 & 0.00610 & 0.00227 & 0.0154 & 0.00168 & 0.00606 & 0.00246 & 0.0575 \\
\hline 700 & 0.00359 & 0.00132 & 0.000987 & 0.00865 & 0.00380 & 0.00512 & 0.00194 & 0.0131 & 0.00143 & 0.00527 & 0.00211 & 0.0473 \\
\hline 800 & 0.00266 & 0.00104 & 0.000801 & 0.00818 & 0.00321 & 0.00420 & 0.00161 & 0.0110 & 0.00122 & 0.00455 & 0.00186 & 0.0402 \\
\hline 900 & 0.00211 & 0.000764 & 0.000651 & 0.00626 & 0.00259 & 0.00359 & 0.00133 & 0.00895 & 0.00104 & 0.00396 & 0.00161 & 0.0329 \\
\hline 1000 & 0.00158 & 0.000654 & 0.000525 & 0.00518 & 0.00215 & 0.00299 & $0.001 u_{4}$ & 0.0081 & 0.000889 & 0.00342 & 0.00141 & 0.0280 \\
\hline
\end{tabular}


TABLE 4* PRIMARY FLUX AND PRTMARY INTENSITIES OF VARIOUS COMPONENTS FROM URANTUM BROAD SOURCE EMITTING I PHOTON PER FT ${ }^{3}$ PER SEC

\begin{tabular}{|c|c|c|c|c|c|c|c|c|c|c|c|c|}
\hline \multirow{3}{*}{$\begin{array}{l}\text { ALTITUDE } \\
\text { (FT) }\end{array}$} & \multicolumn{11}{|c|}{ ENERGY（MEV） } & \multirow{2}{*}{$\begin{array}{c}\text { PRIMARY FLUX } \\
\text { (PHOTONS PER } \\
\text { FT }{ }^{3} \text { PER SEC) }\end{array}$} \\
\hline & 0.609 & 0.769 & 0.934 & 1.120 & 1.238 & 1.378 & 1.509 & 1.764 & 1.848 & 2.204 & 2.432 & \\
\hline & \multicolumn{12}{|c|}{ PRIMARY INTENSITY (PHOTONS PER FT ${ }^{2}$ PER SEC) } \\
\hline 0 & 0.0239 & 0.00573 & 0.00305 & 0.0243 & 0.00926 & 0.0124 & 0.00406 & 0.0246 & 0.00263 & 0.00877 & 0.00333 & 0.121 \\
\hline 100 & 0.0123 & 0.00310 & 0.00174 & 0.0142 & 0.00553 & 0.00700 & 0.00252 & 0.0158 & 0.00170 & 0.00579 & 0.00226 & 0.0718 \\
\hline 200 & 0.00766 & 0.00201 & 0.00117 & 0.00981 & 0.00385 & 0.00496 & 0.00180 & 0.0115 & 0.00125 & 0.00438 & 0.00171 & 0.0503 \\
\hline 300 & 0.00509 & 0.00137 & 0.000829 & 0.00704 & 0.00280 & 0.00366 & 0.00135 & 0.00876 & 0.000953 & 0.00340 & 0.00134 & 0.0367 \\
\hline 400 & 0.00343 & 0.000967 & 0.000601 & 0.00518 & 0.00208 & 0.00276 & 0.001202 & 0.00679 & 0.000741 & 0.00269 & 0.00107 & 0.0274 \\
\hline 500 & 0.00239 & 0.000683 & 0.000440 & 0.00388 & 0.00157 & 0.00212 & 0.000791 & 0.00535 & 0.000585 & 0.00216 & 0.000808 & 0.0208 \\
\hline 600 & 0.00169 & 0.000496 & 0.000333 & 0.00292 & 0.00120 & 0.00163 & 0.000616 & 0.00425 & 0.000466 & 0.00175 & 0.000709 & 0.0161 \\
\hline 700 & 0.00120 & 0.000364 & 0.000247 & 0.00222 & 0.000919 & 0.00127 & 0.000482 & 0.00343 & 0.000373 & 0.00143 & 0.000582 & 0.0126 \\
\hline 800 & 0.000769 & 0.000267 & 0.000187 & 0.00170 & 0.000715 & 0.000962 & 0.000385 & 0.00274 & 0.000301 & 0.00116 & 0.000481 & 0.00969 \\
\hline 900 & 0.000619 & 0.000148 & 0.000143 & 0.00133 & 0.000558 & 0.000789 & 0.000307 & 0.00169 & 0.000244 & 0.000966 & 0.000399 & 0.00772 \\
\hline 1000 & 0.000423 & 0.000148 & 0.0000987 & 0.00104 & 0.000439 & 0.000629 & 0.000244 & 0.00180 & 0.000200 & 0.000793 & 0.000333 & 0.00577 \\
\hline
\end{tabular}


32

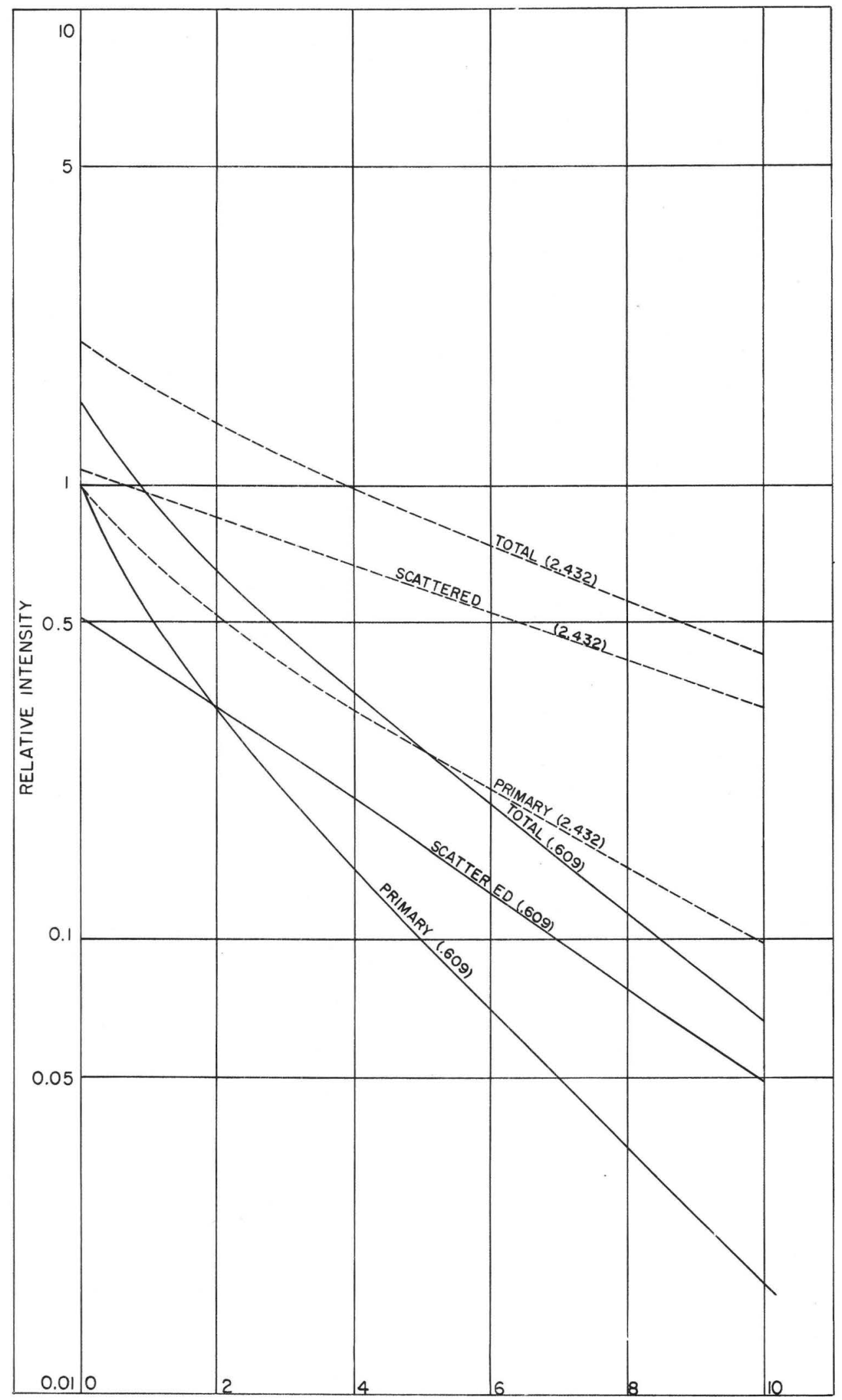

Altitude above source (in hundreds of feet)

FIGURE 6. -RELATIVE VALUES OF PRIMARY, SCATTERED, AND TOTAL INTENSITIES FOR PRIMARY ENERGIES OF 2.432 AND 0.609 MEV, FROM BROAD SOURCE 
In figure 7, the computed total and primary fluxes are compared to the experimental data normalized to the theoretical value at the 500-foot altitude. The large deviation in slope between the curves labelled "data" and "primary" indicates the large contribution from degraded photons. The total flux and data agree well, even though the energy dependence of the detector has not been taken into accourt." The steeper slope of the computed curve relative to the experimental curve is to be expected because the computation weights all energies equally whereas scintillation detectors are more efficient in detecting the low energies, both primary and scattered and the fractional contribution of primary flux to the total flux decreases with increasing distance from the source. Absolute agreement of computed with experimental data cannot be demonstrated as the true spectral efficiency of the detector is not known. However, one can compute the overall efficiency at 500 feet. Under the assumptions of two gamma rays per disintegration of radium, a density of 2.3 for the source, a source concentration of 0.0013 percent $\mathrm{eU}_{3} \mathrm{O}_{8}$, and a detector area of 0.25 square feet, the expected counting rate is 597 counts per sec for a 100 percent efficient detector. As the experimental counting rate is 64 counts per sec, the efficiency of the detector used is about 17 percent. 


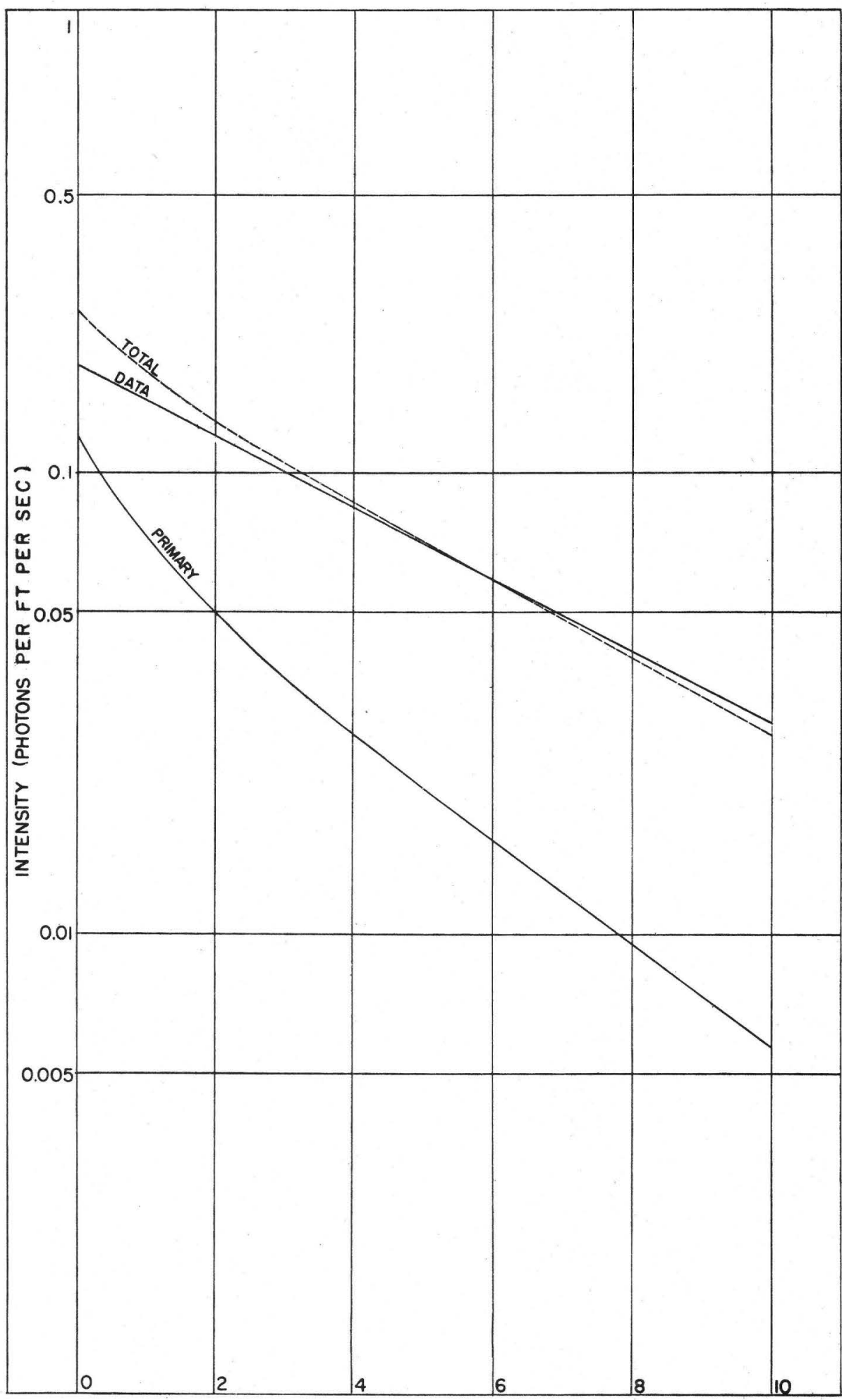

Altifude above source (in hundreds of feet)

FIGURE 7. - COMPUTED TOTAL AND PRIMARY FLUXES FROM BROAD SOURCE OF URANIUM EMITTING ONE PHOTON PER FT 3 PER SEC. DATA HAVE BEEN NOR-MALIZED TO AGREE WITH COMPUTATION AT 500 FT ABOVE SOURCE 
The decomposition of the flux and intensity from both an elementary and point sources of uranium are presented graphically in figures 8 through 11 in order to show the relative contribution of both primary and scattered radiation. The total primary flux (fig. 8) from a broad source is decomposed into the contributions from each of the primary energies given in table 2. For an elementary source, the calculated flux and intensities normalized to the emission of one photon per foot per second are given in tables 5 and 6 and plotted in figures 9,10 , and 11. The relative primary, scattered, and total intensities from 0.609 and $2.432 \mathrm{Mev}$ primary gamma rays are presented in figure 9. The scattered intensity is again a significant proportion of the total intensity. A comparison of primary, total, and measured fluxes from an elementary source is given in figure 9 , the source data being adjusted to agree with the computed total flux at 500 feet. The agreement in general behavior is excellent, the discrepancy, again, being due to the equal weighting of energies in the computation. Finally, the decomposition of the total flux into contributions from each energy is shown in figure 11. 
TABLE 5. TOTAL FLUX AND TOTAL INTENSITIES OF VARIOUS COMPONENTS FROM URANTUM ELEMENTARY SOURCE EMITTITNG 1 PHOTON PER FT PER SEC

\begin{tabular}{|c|c|c|c|c|c|c|c|c|c|c|c|c|}
\hline \multirow[t]{3}{*}{ ALTITUDE (FT) } & \multicolumn{11}{|c|}{ ENERGY (MEV) } & $\begin{array}{l}\text { TOTAL FLUX } \\
\text { (PHOTONS PER } \\
\text { FT }{ }^{2} \text { PER SEC) }\end{array}$ \\
\hline & 0.609 & 0.769 & 0.934 & 1.120 & 1.238 & 1.378 & 1.509 & 1.764 & 1.848 & 2.204 & 2.432 & \\
\hline & \multicolumn{12}{|c|}{ TOTAL INTENSITY (PHOTONS PER FT PER SEC) } \\
\hline 100 & $6.58 \times 10^{-7}$ & $1.37 \times 10^{-7}$ & $8.05 \times 10^{-8}$ & $6.80 \times 10^{-7}$ & $2.62 \times 10^{-7}$ & $3.31 \times 10^{-7}$ & $1.19 \times 10^{-7}$ & $7.34 \times 10^{-7}$ & $7.88 \times 10^{-8}$ & $2.69 \times 10^{-7}$ & $2.03 \times 10^{-7}$ & $3.45 \times 10^{-6}$ \\
\hline 200 & 1.35 & 0.294 & 1.76 & 1.54 & 0.597 & 0.756 & 0.271 & 1.70 & 1.84 & 0.630 & 0.243 & 0.774 \\
\hline 300 & 0.503 & 0.1114 & 0.714 & 0.617 & 0.241 & 0.306 & 0.113 & 0.696 & 0.754 & 0.261 & 0.102 & 0.310 \\
\hline 400 & 0.144 & 0.0553 & 0.357 & 0.352 & 0.122 & 0.157 & 0.0567 & 0.361 & 0.391 & 0.136 & 0.0528 & 0.151 \\
\hline 500 & 0.113 & 0.0304 & 0.202 & 0.177 & 0.0697 & 0.0911 & 0.0327 & 0.212 & 0.230 & 0.0810 & 0.0313 & 0.0881 \\
\hline 600 & 0.0683 & 0.0186 & 0.124 & 0.110 & 0.0441 & 0.0584 & 0.0207 & 0.134 & 0.146 & 0.0514 & 0.0203 & 0.0553 \\
\hline 700 & 0.0401 & 0.0114 & 0.0796 & 0.0717 & 0.0286 & 0.0373 & 0.0139 & 0.0900 & 0.0979 & 0.0350 & 0.0136 & 0.0359 \\
\hline
\end{tabular}


TABLE 6. PRIMARY FLUX AND PRIMARY INTENSITIES OF VARIOUS COMPONENTS FROM URANTUM ELEMENTARY SOURCE EMITTING I PHOTON PER FT PER SEC

\begin{tabular}{|c|c|c|c|c|c|c|c|c|c|c|c|c|}
\hline \multirow[t]{3}{*}{ ALTITUDE (FT) } & \multicolumn{11}{|c|}{ ENERGY (MEV) } & \multirow{2}{*}{$\begin{array}{l}\text { PRIMARY FLUX } \\
\text { (PHNTONS PER } \\
\text { FT }^{2} \text { PER SEC) }\end{array}$} \\
\hline & 0.609 & 0.769 & 0.934 & 1.120 & 1.238 & 1.378 & 1.509 & 1.764 & 1.848 & 2.204 & 2.432 & \\
\hline & \multicolumn{12}{|c|}{ PRTMARY INTENSITY (PHOTONS PER FT ${ }^{2}$ PER SEC) } \\
\hline 100 & $2.96 \times 10^{-7}$ & $7.25 \times 10^{-7}$ & $3.98 \times 10^{-8}$ & $3.19 \times 10^{-7}$ & $1.23 \times 10^{-7}$ & $1.53 \times 10^{-7}$ & $5.49 \times 10^{-8}$ & $3.37 \times 10^{-7}$ & $3.63 \times 10^{-8}$ & $1.22 \times 10^{-7}$ & $4.66 \times 10^{-8}$ & $1.60 \times 10^{-6}$ \\
\hline 200 & 0.573 & 1.44 & 0.807 & 0.660 & 0.255 & 0.323 & 1.16 & 0.724 & 0.782 & 0.268 & 1.03 & 0.332 \\
\hline 300 & 0.198 & 0.510 & 0.294 & 0.243 & 0.0946 & 0.121 & 0.440 & 0.277 & 0.300 & 0.104 & 0.402 & 0.123 \\
\hline 400 & 0.0731 & 0.228 & 0.135 & 0.128 & 0.0444 & 0.0574 & 0.210 & 0.134 & 0.146 & 0.0512 & 0.199 & 0.0580 \\
\hline 500 & 0.0402 & 0.116 & 0.0706 & 0.0597 & 0.0237 & 0.0310 & 0.1214 & 0.0739 & 0.0806 & 0.0287 & 0.112 & 0.0307 \\
\hline 600 & 0.0231 & 0.0641 & 0.0400 & 0.0343 & 0.0137 & 0.0181 & 0.0672 & 0.0441 & 0.0483 & 0.0174 & 0.0686 & 0.0180 \\
\hline 700 & 0.0131 & 0.0375 & 0.0240 & 0.0208 & 0.00839 & 0.0112 & 0.0419 & 0.0279 & 0.0306 & 0.0112 & 0.0444 & 0.0110 \\
\hline
\end{tabular}




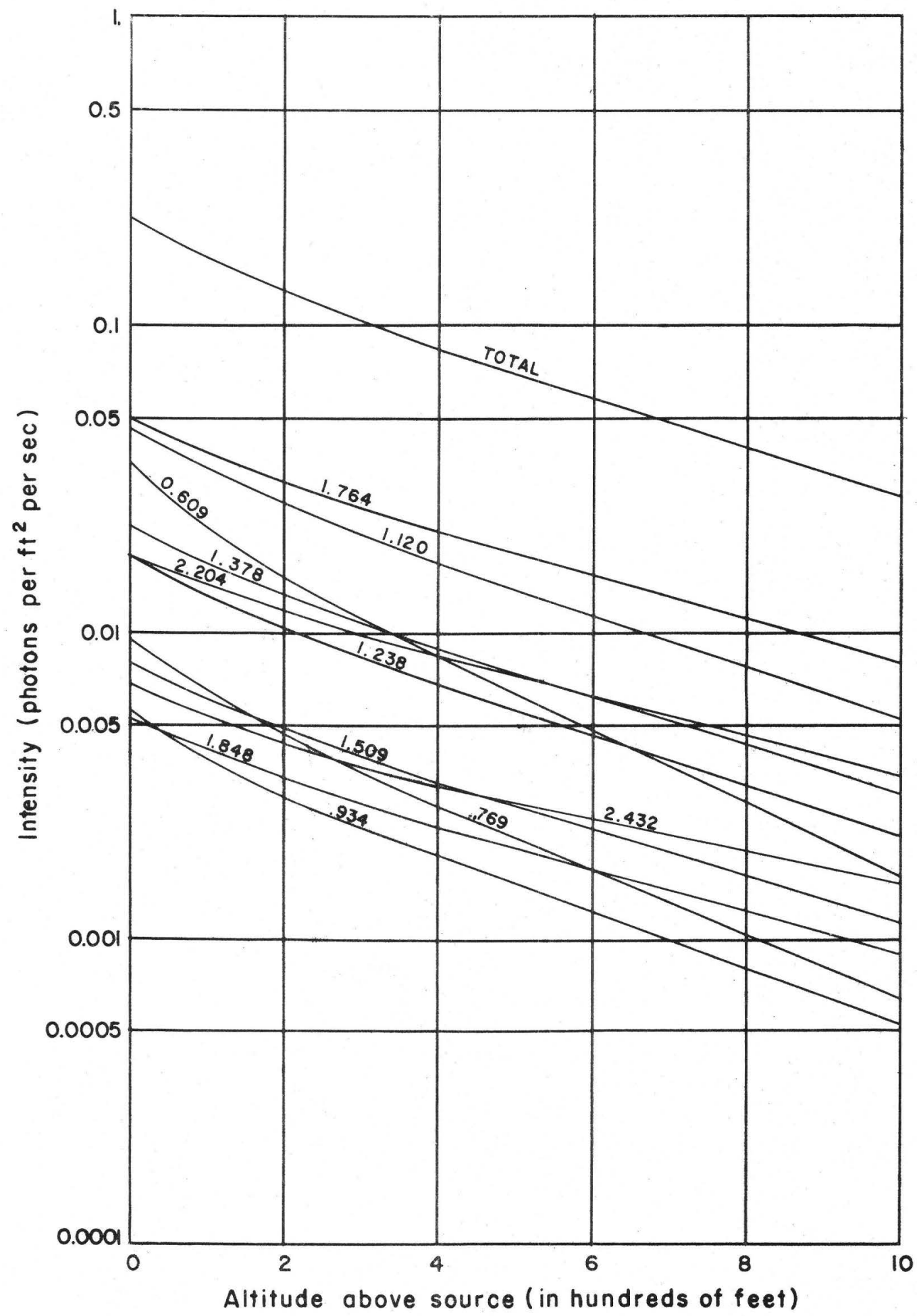

FIGURE 8.- DECOMPOSITION OF TOTAL FLUX FROM BROAD SOURCE OF URANIUM EMITTING ONE PHOTON PER FT ${ }^{3}$ PER SEC INTO CONTRIBUTION FROM VARIOUS LINES OF SPECTRUM. NUMBERS DENOTE ENERGY IN MEV OF VARIOUS PRIMARY COMPONENTS GIVING RISE TO TOTAL INTENSITIES REPRESENTED BY CURVES 


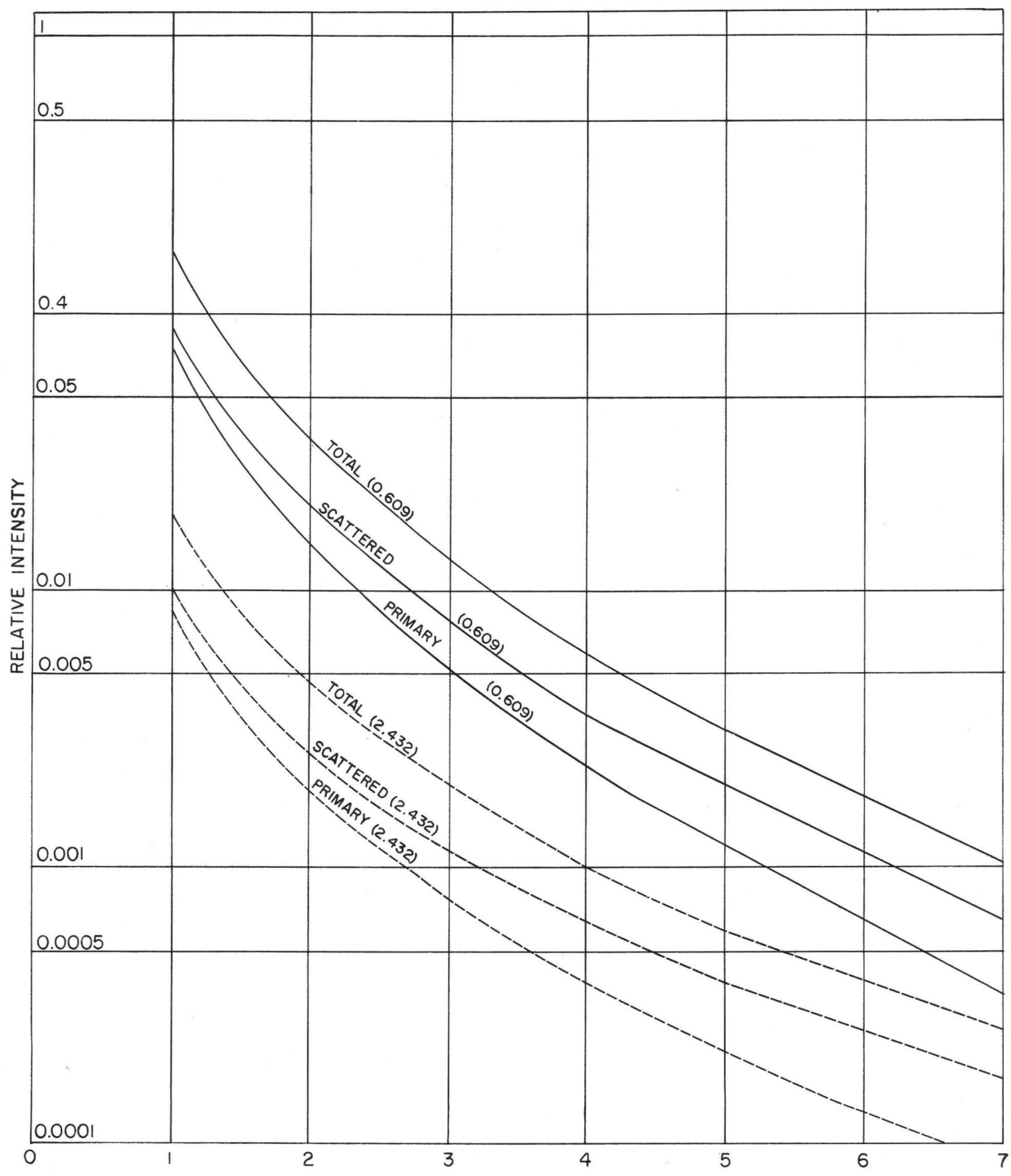

Altitude above source (in hundreds of feet)

FIGURE 9.-RELATIVE VALUES OF PRIMARY, SCATTERED, AND TOTAL INTENSITIES FOR PRIMARY ENERGIES OF 


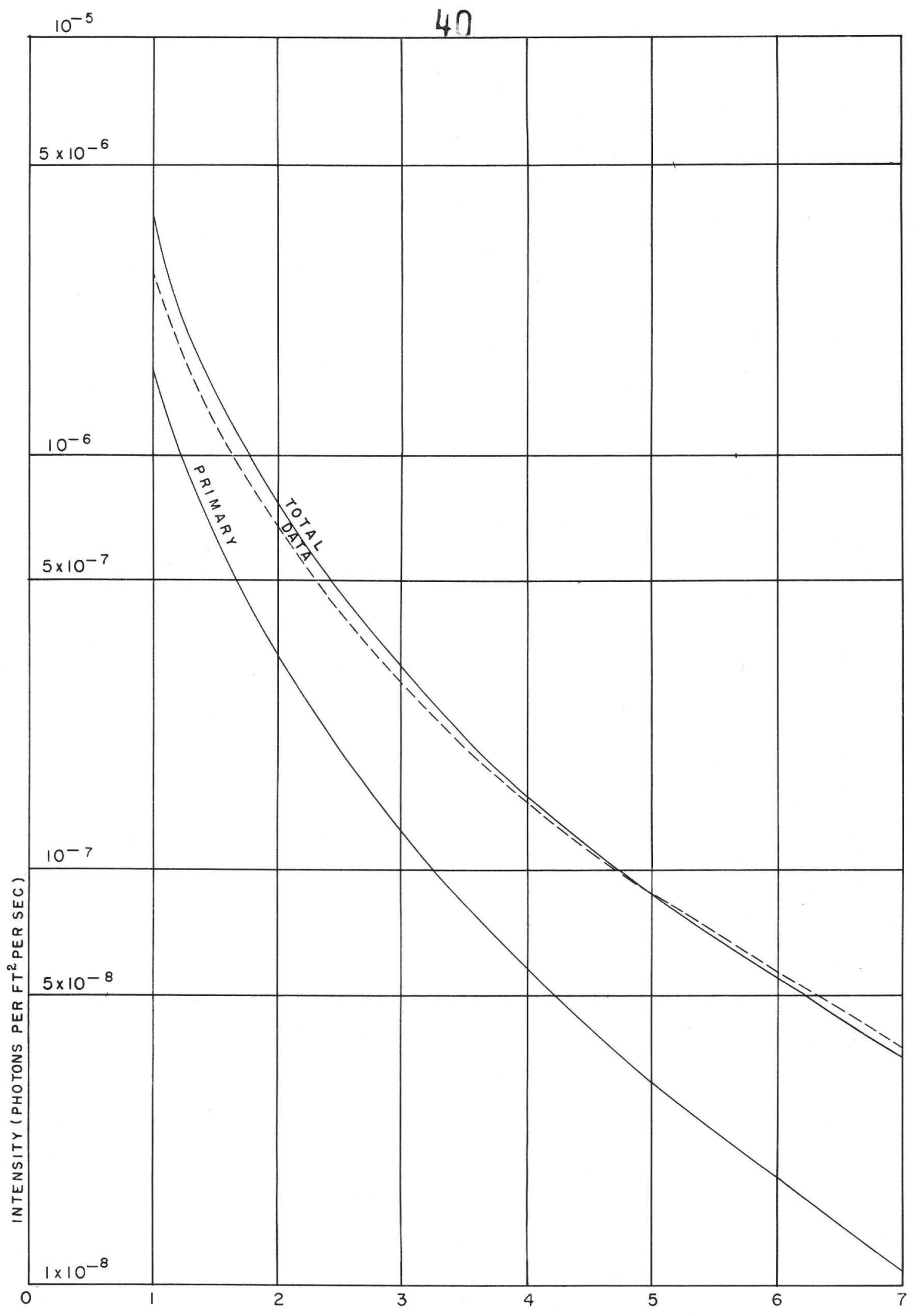

Altitude above source (in hundreds of feet)

FIGURE 10- COMPUTED TOTAL AND PRIMARY FLUXES FROM

ELEMENTARY SOURCE OF URANIUM EMITTING I PHOTON PER FT PER SEC DATA WERE NORMALIZED TO AGREE WITH COMPUTATION AT 500 FT ABOVE SOURCE

87182 
41.

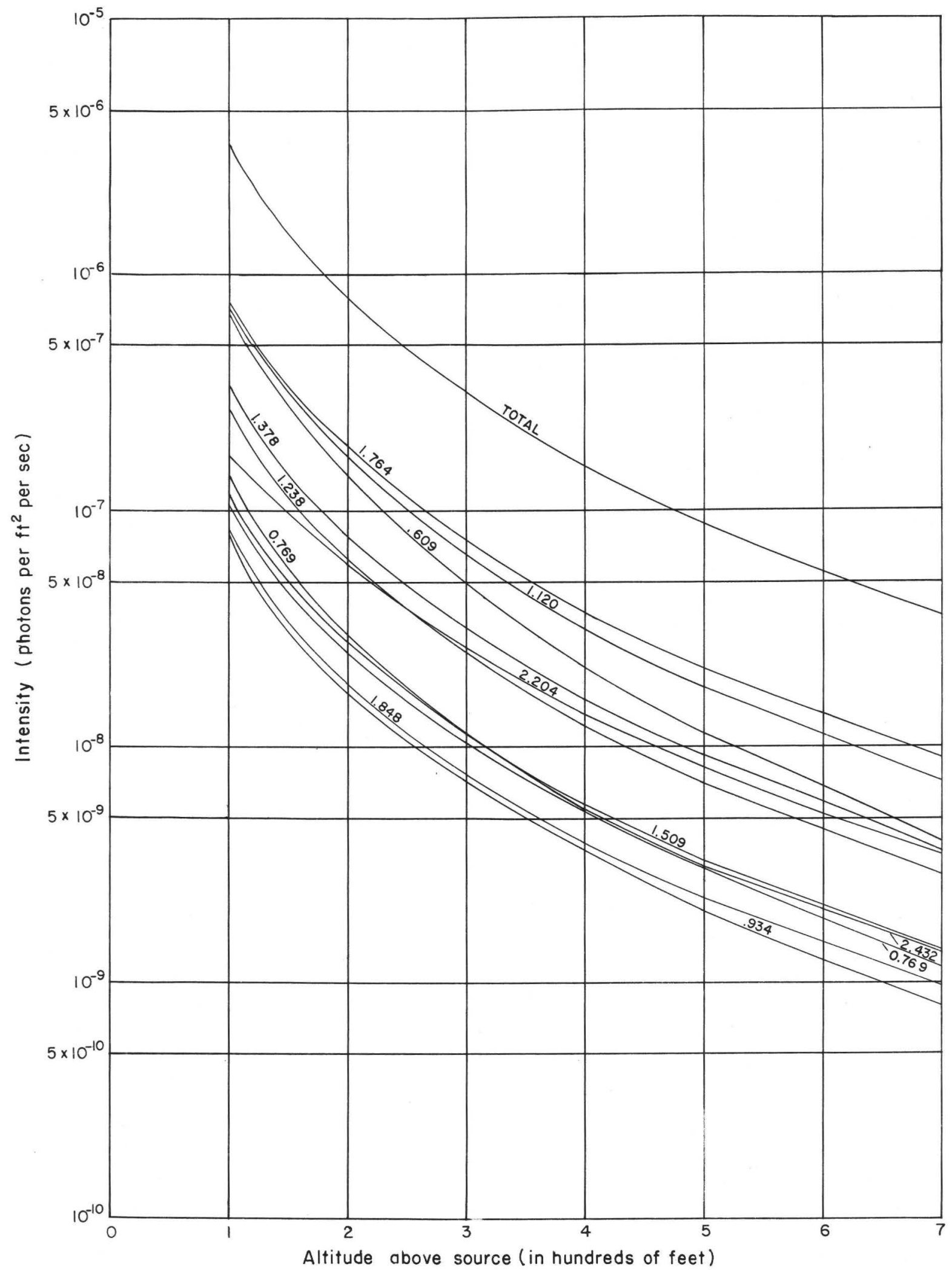

FIGURE II.-DECOMPOSITION OF TOTAL FLUX FROM ELEMENTARY SOURCE OF URANIUM EMITTING ONE PHOTON PER FT PER SEC INTO CONTRIBUTION FROM VARIOUS LINES OF SPECTRUM. NUMBERS DENOTE ENERGY IN MEV OF VARIOU! PRIMARY COMPONENTS GIVING RISE TO TOTAL INTENSITIES REPRESENTED BY CURVES 
EFFECT OF TIME CONSTANT AND THE CONE OF RESPONSE

As computed in Appendix II, a continuously-recording radiation detector in an aircraft flying at 500-foot altitude at $220 \mathrm{ft}$ per sec directly over a point source will record 87 percent of the stationary value signal, whereas the same detector in an aircraft flying at 100foot altitude at $88 \mathrm{ft}$ per sec will record only 76 percent of the stationary value. The lag in recording the peak response at the 500foot and the 100-foot altitudes will be 0.320 and 0.675 of the time constant respectively. Also, it may be seen from Appendix II, formula 6, that for low flying aircraft, a decrease in the product of velocity and time constant and (or) an increase in the cone of response will give an increased response. For high flying aircraft the product of velocity and time constant should be made as low as possible.

\section{CONCLUSIONS}

Formulas based on theoretical considerations are presented for the intensity of both the elementary and broad sources. The constants which appear in both expressions are determined by fitting the expressions to observed point and broad source data. 
Comparison of experimental data with theoretical calculations shows excellent agreement for both the broad and the elementary sources. Moreover, this agreement of experimental data with computation (which involves the assumption of non-energy-dependent detector) shows the feasibility of using the derived empirical expressions for various scintillation detectors by the mere change of a multiplicative constant. The theoretical calculations show that the major portion of the radiation intensity at a considerable air distance above a thick uranium source is the scattered radiation intensity.

It should be pointed out that the data of tables 3 and 4 can be adjusted for altitudes above sea level other than that at Grand Junction, Colorado, by using the appropriate $\mu$, a function of air density, to correct tabulated values for various air distances from the source. The values in tables 5 and 6 can be similarly adjusted after multiplying by $x^{2}$ since in this case $r=x$. The density of the source was taken to be 2.3; for other densities, corrections should be applied inversely as the densities. 
The following three concepts underlying this particular semiempirical approach are considered significant:

Use of an elementary source of infinite thickness instead of the classical "point" source. In calculating the intensity of a theoretical point source located at an interface, it is necessary to take into account scattering and absorption at and near the interface. This is circumvented by observing the radiation intensity from an elementary source of infinite thickness, because the measurements themselves already contain the effects of both scattering and absorption.

Use of the form and structure predicted by theory to establish an analytical expression for the elementary source behavior which will integrate to the broad source expression.

Use of the experimental data for the elementary and broad sources to determine the constants in the elementary source function. 


\section{LITERATURE CITED}

Cook, J. C., 1952, An analysis of airborne surveying for surface radioactivity: Geophysics, v. 17, no. 3, p. 607-706.

Fano, U., 1953a, Penetration of X- and gamma-rays to extremely great depth: U. S. Nat. Bur. Standards Jour. Research, v. 51, no. 2, p. 95-121.

1953b, Gamma-ray attenuation: Nucleonics, v. 11, no. 8, p. 8-12; no. 9, p. 55-61.

Goldstein, H. and Wilkins, J. H., 1954, Calculations of the penetration of gamma-rays, final report: U. S. Atomic Energy Comm. NYO-3075, issued by U. S. Atomic Energy Comm. Tech. Inf. Service, Oak Ridge.

Mladjenovic, M. and Hedgran, Arne, 1954, An investigation of the Compton secondaries from RaC gamma rays: Arkiv for Fysik, Band. 8, Hafte 4, p. 49-63.

Mladjenovic, M. and Slatis, H., 1954, Internal conversion spectrum of the active deposit of radon: Arkiv for Fysik, Band 8, Häfte 4, p. $65-82$.

Peirson, D. H. and Franklin, E., 1951, Aerial prospecting for radioactive minerals: British Jour. Applied Physics, v. 2, p. 281-291. Spencer, L. V. and Fano, U., 1951, Penetration and diffusion of x-rays. Calculation of spatial distribution by polynomial expansion: U. S. Nat1.Bur. Standards Jour. Research, v. 46, no. 2, p. 446-456. 
Stead, $F_{0} W_{0}, 1955$, Instruments and techniques for measuring radioactivity in the field: Contribution to the International

Conference on Peaceful Uses of Atomic Energy, Geneva, Switzerland; Paper R. 1.1-1037。

Steljes, F., Cowper, G., and Carmichael, H., 1952, Aerial prospecting for radioactive material: Canada Natl. Research Council, Rept. no. CRR -495 . 


\section{APPENDIX I. COMPUTATION OF INTENSITIES}

The computed values (Goldstein, 1954) are the quantities $4 \pi r^{2} I_{0}\left(\mu_{i} r, E, E_{i}\right)$ where $I_{0}\left(\mu_{i} r, E, E_{i}\right)$ are the scattered energy flux at energy, E, distance, $r$, from the source, originating from a point source of energy $E_{i}$ and strength $I$ photon per second, for various media. $\boldsymbol{\mu}_{i}$ is the linear attenuation coefficient. Compton scatterer was the medium chosen to be most similar to air in the published tabulations.

The quantity

$$
B\left(\mu_{i} r, E_{i}\right)=\int_{.4}^{E_{i}} 4 \pi r^{2} I_{0}\left(\mu_{i} r, E, E_{i}\right) \frac{d E}{E}
$$

was computed for energies $E_{i}=0.5,1.0,2.0,3.0$, and $4.0 \mathrm{Mev}$, and $\mu_{i} r=1,2,7,10,15$, and 20. The trapezoidal rule was used except at the end points where linear interpolation was followed by direct integration of the interpolant. Then quadratic interpolation was performed over these to find $B\left(\mu_{i} r, E_{i}\right)$ for the 11 primary energies of the uranium series. The result was 77 values of $B\left(\mu_{i} r, E_{i}\right)$ 。 
48

As the solution of multimedia Boltzmann equation of pure -Compton scatterer in one distance variable can be cast into one medium form, an exact solution can be obtained for the broad source by computing as though the media were homogeneous

$$
\begin{aligned}
& I_{b}\left(x, E_{i}\right)=\int_{0}^{\cos -1} x / r \int_{y}^{\infty} \frac{e^{-\mu_{i} r}}{4 \mu r^{2}} B\left(\mu_{i} r_{s} E_{1}\right) 2 \pi r^{2} d r \sin \theta d \theta \\
& =\frac{e^{-\mu_{i}^{s} y}}{2 \mu_{i}^{s}} \int_{0}^{\infty} \frac{u}{u+\mu_{i}^{s} y} B\left(u+\mu_{i}^{s} y_{g} E_{i}\right) e^{-u} d u \\
& \equiv \frac{e^{-\mu_{i}^{4} x}}{2 \mu_{i}^{s}} \int_{0}^{\infty} \frac{u}{u+\mu_{i}{ }^{4} x} B\left(u+\mu_{i}^{4} x_{,} E_{i}\right) e^{-u} d u \\
& \mu_{i}^{s} y \equiv \mu_{i}^{a} x
\end{aligned}
$$

(2) 
For the case of an elementary source, such an equality does not exist, and we assume that the two media point source expression is given as $\frac{1}{r^{2}} f\left(\mu_{i}^{s}(r-x)+\mu_{i}^{a} x\right)$ wherein the scattered intensity at point $\mathrm{x}$ directly over head is:

$$
\begin{aligned}
& I_{p}\left(x, E_{i}\right)=\int_{x}^{\infty} \frac{e^{-\mu_{i}^{s}(r-x)-\mu_{i}{ }^{4} x}}{4 \pi r^{2}} d r B\left(\mu_{i}^{s}(r-x)+\mu_{i}^{4} x\right) \\
& =\frac{e^{-\mu_{i}^{4} x}}{4 \pi} \mu_{i}^{s} \int_{0}^{\infty} \frac{e^{-u}}{\left(u+\mu_{i}^{s} x\right)^{2}} B\left(u+\mu_{i} x^{2} E_{i}\right) d u
\end{aligned}
$$

which is not exact. The integrations in either case are performed by the method of Gauss wherein

$$
\int_{0}^{\infty} f(x) e^{-x} d x \sim \sum_{k=1}^{n_{j}}\left[\frac{d I_{n}(x)}{d x}\right]_{x=x_{k}}^{-2} \quad f\left(x_{k}\right)
$$

where $L_{n}\left(x_{k}\right)=0, x_{k}^{\prime}$ s being the $n$ roots of Laguerre Polynomial of order $n$.

Thus

$I_{b}\left(x, E_{i}\right) \sim{\frac{e^{-\mu_{i}}}{2 \mu_{i}^{s}}}_{\sum_{k=1}^{5}}^{\frac{1}{d L_{5}(x)}}{ }_{x=x_{k}}^{d x} B\left(x_{k}+\mu_{i}^{4} x, E_{i}\right) \frac{x_{k}}{x_{k}+\mu_{i} x}$

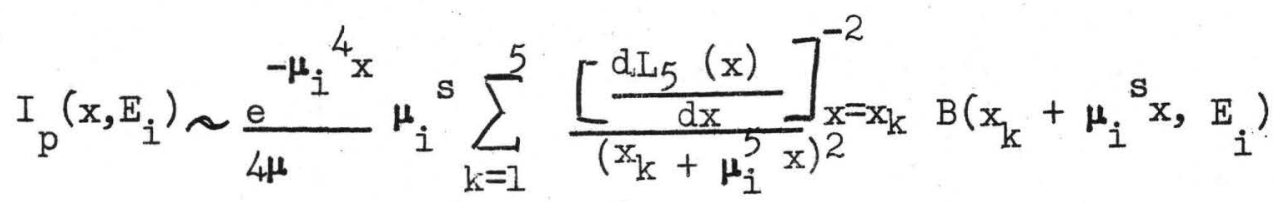

The B's were plotted on log-log papers and read off the graph for 5 values of the argument for each $\mathrm{x}$ point and energy value. 
The primary expressions can be readily found.

$$
\begin{aligned}
& I_{b}^{0}\left(x, E_{i}\right)=\frac{1}{2 \mu_{i}^{s}} \int_{1}^{\infty} \frac{e^{-\mu_{i}^{s} x y}}{y^{2}} d y \\
& I_{p}\left(x_{2} E_{i}\right)=\frac{1}{4 \pi} \frac{e^{-\mu_{i}}}{\mu_{i}^{s}}\left[e^{\mu_{i} s} \int_{1}^{\infty} \frac{e^{-\mu_{i}{ }^{s} x y}}{y^{2}} d y\right] \sim \frac{1}{4 \pi \mu_{s}} \frac{e^{-\mu_{i}^{a}}}{x^{2}}
\end{aligned}
$$

Expressions (7) and (8) multiplied by the relative abundance of table 2 are listed in tables 4 and 6 under their respective energy headings for various values of $x_{0}$. The final column is the sum of all these components.

The sum of (7) and (5) and the sum of (6) and (8) multiplied by the relative abundances are found in tables 3 and 5 under respective energy headings. The final column again represents the sum.

The superscripts a and $\mathrm{s}$ refer to air and source respectively. 


\section{APPENDIX II. CALCULATION OF DETECTOR RESPONSE}

The relative response of a counting ratemeter at time $t$ to a point source of intensity I is

$$
R(t)=\int_{t}^{t_{0}} e^{-\left(t-t^{8}\right)} I\left(t^{8}\right) d t^{8}
$$

where time is expressed in units of the time constant, $T$, of the instrument, $t_{0}$ is the time the source first falls within the cone of response of the detector ${ }_{2}$ and the origin of time is chosen as the moment of closest approach. Expansion about $t=0$ exists for this integral, $i . e_{\circ}$,

$$
R(t)=\left.\sum_{m=0}^{\infty} \frac{d^{n} R(t)}{d t^{n}}\right|_{t=0} \frac{t^{n}}{n !}
$$

where the derivatives satisfy the relationship

$$
\begin{aligned}
& \left.\frac{d^{n} R(t)}{d t^{n}}=-\frac{d^{n-I} R(t)}{d t^{n-1}}+\frac{d^{n-I} I(t)}{d t^{n-1}}\right]_{t=0} \\
& R(0)=\int_{0}^{t_{0}} e^{\infty y} f(z) d t^{3} \\
& y=t^{4}+z \quad z^{2}=x^{2}+z^{2}+\beta^{2} t^{2}=r^{2}+\beta^{2} t
\end{aligned}
$$

where:

$$
\begin{aligned}
& x=\text { altitude in mean free paths } \\
& z=\text { ground projection of distance of closest approach } \\
& \beta=\text { distance traveled in one time constant in mean free paths } \\
& t_{0}=\frac{x^{2} \tan ^{2} \alpha-z^{2}}{\beta} \\
& \alpha=1 / 2 \text { angle of the cone of response }
\end{aligned}
$$


Then, by partial integration

$$
\left.R(0) \sim \frac{-e^{-y} f(z)}{\frac{d y}{d t^{r}}}-\frac{e^{-y}}{\left(\frac{d y}{d t^{r}}\right)} \frac{d}{d t^{r}}\left(\frac{f(z)}{\frac{d y}{d t^{\prime}}}\right)\right]_{0}^{t_{0}}
$$

Because the result of the partial integration is a semi-convergent series, within the range of parameters pertinent to airborne surveying, the minimum error is incurred by evaluating only the first term at the upper limit, and both terms at the lower limit.

$$
R(0) \sim e^{-r} f(r)\left\{(1-\tilde{\omega})-\frac{\beta^{2}}{r}\right\}
$$

where

$$
\begin{aligned}
& \tilde{\omega}=\frac{e^{-z_{0}} f\left(z_{0}\right) e^{-t_{0}}}{\left[1+\beta^{2}-\frac{t_{0}}{z_{0}}\right] e^{-r_{f}}(r)} \\
& z=x \sec \alpha
\end{aligned}
$$

Then the ratio of the response to the stationary value at the point of closest approach is

$$
\frac{R(t)}{e^{-r_{f}(r)}}=\sum_{n=0}^{\infty} \frac{A_{n} t^{n}}{n !}
$$

where

$$
\begin{aligned}
& A_{0}=1-\omega-\frac{\beta^{2}}{r} \\
& A_{1}=\tilde{\omega}+\frac{\beta^{2}}{r} \\
& A_{2}=-\tilde{\omega}-\frac{\beta^{2}}{r} \\
& A_{3}=\tilde{\omega}+\frac{f^{\prime}(r)}{f(r)} \frac{\beta^{2}}{r}
\end{aligned}
$$




$$
A_{4}=-\left(\widetilde{\omega}+\frac{f^{\prime}(r)}{f(r)} \frac{\beta^{2}}{x}\right)
$$

The maximum is found from the equation

$$
\sum_{n=1}^{\infty} \frac{A_{n} t^{n-1}}{(n-1) !}=0
$$

If we retain only two terms, we find

$$
t_{2}=1
$$

the same result as found by Peirson (1951). If we retain three terms

$$
t_{3}=\frac{-A_{2}+\sqrt{A_{2}^{2}}-2 A_{1} A_{3}}{2}
$$

If we retain four terms, we can expand the cubic about $t_{3}$ to a linear term and find

$$
\frac{t_{4}}{t_{3}} \sim 1-\frac{A_{4}}{A_{2}+A_{3}} \frac{t_{3}}{3 !}
$$

Then the insertion of $t_{4}$ into expression (7) yields the ratio of peak response to the stationary value. This is carried out for

$$
\begin{aligned}
\alpha & =45^{\circ}, z=0, \text { and } & \tau & =1 \text { second for two typical cases: } \\
x & =0.730 \text { (500 feet) } & x & =0.146 \text { (100 feet) } \\
\beta & =0.329(220 \mathrm{fps}) & \beta & =0.128 \text { (88 fps relocity) } \\
t_{2} & =1 & t_{2} & =1 \\
t_{3} & =0.323 & t_{3} & =0.635 \\
t_{4} & =0.320 & t_{4} & =0.675 \\
\hline R\left(t_{4}\right) & \frac{R\left(t_{4}\right)}{e^{-x} f(x)} & \frac{e^{-x_{f}(x)}}{f} &
\end{aligned}
$$


It should be noted that due to the nature of the approximation the result can be considered the lower limit of the peak response. To recapitulate, the ratio of peak response to stationary value is

$$
\begin{aligned}
& \frac{R(t)}{e^{-r_{f}(r)} \sim\left(1-\tilde{\omega}-\frac{\beta^{2}}{r}\right)+\left(\tilde{\omega}+\frac{\beta^{2}}{r}\right) t-\left(\tilde{\omega}+\frac{\beta^{2}}{r}\right) \frac{t^{2}}{2 !}} \\
&+\left(\tilde{\omega}+\frac{\beta^{2}}{r} \frac{f^{\prime}(r)}{f(r)}\right) \frac{t^{3}}{3 !}-\left(\tilde{\omega}+\frac{\beta^{2}}{r} \frac{f^{\prime}(r)}{f(r)}\right) \frac{t^{4}}{4 !}
\end{aligned}
$$

where

$$
\begin{aligned}
& \frac{t}{t_{3}}=1-\frac{\tilde{\omega}_{+} \frac{\beta^{2}}{r} \frac{f^{\prime}(r)}{f(r)}}{1-\frac{\beta^{2}}{r} \frac{f^{\prime}(r)}{f(r)}} \frac{t_{3}}{3 !} \\
& t_{3}=\frac{\left(\widetilde{\omega}+\frac{\left.\beta^{2}\right)}{r}+\sqrt{\left(\tilde{\omega}+\frac{\beta^{2}}{r}\right)^{2}-2\left(\widetilde{\omega}+\frac{\beta^{2}}{r}\right)\left(\tilde{\omega}_{+} \frac{\beta^{2}}{r} \frac{f^{\prime}(r)}{f(r)}\right.}\right.}{}
\end{aligned}
$$


PART 2

\author{
GAMMA-RAY INTENSITY FROM IDEALIZED SOURCES \\ AND INTERPRETATION OF RADIOACTIVITY ANOMALIES
}

\title{
ABSTRACT
}

Gamma-ray intensities from idealized sources, selected to approximate most nearly naturally occurring sources, have been computed from the elementary and broad source behavior established in Part 1. All computations are based on the assumptions of quarter-mile flight-line spacing, and flight path at 500 feet above the ground; the computed data are strictly valid only for these conditions of airborne radioactivity surveying and for scintillation detectors of essentially identical spectral energy response。

The intensities and areas under the curve that would be recorded by a counting-rate meter have been computed for four selected source types, the elementary (point), the finite (circular), the slab (line), and the broad (semi-infinite) source. The peak intensity and the area under the curve are the two interrelated observable quantities most useful for interpretation. The shape of recorded anomalies as shown by analysis of experimental and computed data cannot be used for interpreting grade-area and (or) grade of natural sources, although shape is useful in determining source type. 
In interpreting anomalies, three of the four source types can be distinguished by the appearance of an anomaly, either on one or on two or more adjacent flight lines; the fourth type, the broad source, can be readily distinguished by flattening of the anomaly on adjacent flight lines. With source type identified, the grade-area and (or) grade of a natural source can be determined from tabulated data for the two observable quantities, the peak intensity and the area under the curve. The accuracy of interpretation of grade of broad and slab sources has been confirmed by field investigations; the interpretation of gradearea and (or) grade of finite and elementary sources, particularly those visible on only. one flight line, is difficult and is satisfactory only within an order of magnitude.

The method of interpretation, based on a semi-empirical approach, is applicable to measurements made with scintillation detectors of broad spectral energy response. For other than essentially identical radiation detection instruments, the necessary constants which specify the buildup factor for any specific detector can be established by empirical tests of the response to known thick uranium sources. 


\section{INTRODUCTION}

In Part I, semi-empirical expressions of general validity were developed for the gamma-radiation intensities at considerable air distances from the two extreme types of natural, thick uranium sources, the elementary source and the broad source. To interpret semiquantitatively the measurements made in airborne radioactivity surveying, quantitative relationships must be established between the characteristics of natural sources intermediate between the two extremes of natural source types, and the various observable quantities recorded by a specific detector of the counting rate-meter type, such as the peak intensity, the area under the curve, and the shape of the curve.

In this section, expressions are established for the intensities from the line, slab, and the finite sources, and the areas under the peak of a counting rate-meter curve for the elementary, line, slab and finite sources. 
The unknown factors that enter into the interpretation of an anomaly are the source position relative to the detector, the surface dimension of the source, and the source strength in terms of equivalent uranium content. As the usual practice in airborne radioactivity surveying is to make continuously recorded measurements along equally spaced, constant-altitude flight lines, the location of an anomaly along the direction of flight can be determined with relatively small error. The location of an anomalous source is thus reduced to one unknown, the distance along the line normal to the flight path which passes through the peak position of the anomaly. If either linear or circular symmetry is assumed, the surface dimensions of the source are reduced to one variable, either the breadth of a slab source or the radius of a finite circular source.

The three unknowns for any given source must be related to the observable data. The most obvious is the peak intensity; another is the area under the curve. A third is the shape of the curve, characterized by the slope or by the width at half maximum intensity.

Computation of the peak intensities and areas under the curves for selected sources are made and criteria for distinguishing the various source types are established. Then the observable data are expressed directly in terms of source characteristics, eliminating explicit reference to the (unknown) distance between the source and the detector. Moreover, as natural sources vary greatly in grade, some grade-independent quantities readily computable from observable data should be used to determine salient characteristics of the sources. 


\section{Acknowledgments}

The author is grateful to L. V. Spencer of National Bureau of Standards for an enlightening discussion on gamma-ray scattering theory and for the tedious task of checking the mathematics.

The work herein reported is part of an investigation being carried on by the U. S. Geological Survey on behalf of the Division of Research of the U. S. Atomic Energy Commission.

\section{SELECTED IDEALIZED SOURCES}

The general behavior of the radiation intensities from natural sources is best discussed in terms of a few sources selected to approximate most nearly natural configurations. All of these sources are assumed to be infinite in depth extent. (Because of the absorption of radiation within the source, a thickness of one foot may be considered infinite.)

A. Elementary source. An elementary source is one whose areal extent is sufficiently small so that the radiation anomaly produced by it is identical to that produced by a theoretical point source. The intensity, $I_{p}(x, \rho, a)$, from an elementary source, (See figure 1 in section $I_{s}$ ) is a function of $\mathrm{x}_{9}$ the altitude of the detector above the source plane; $P$, the source plane projection of the air distance between the source center and the detector; and $a$, the radius of the source. The area under the curve recorded by a count rate-meter, $\mathrm{H}_{\mathrm{p}}\left(\mathrm{x}_{\mathrm{g}} \mathrm{z}, \mathrm{a}\right)$ is a function of previously defined $x$ and $a_{9}$ and $z$, the source plane projection of the air distance of nearest approach between the detector and source center. 
B. Broad source. A broad source is so large in areal extent that the intensities over the central region remain constant no matter how much additional source material is added to its boundary. The intensity, $I_{b}(x)$, from a broad source, (See figure 2, , part 1 ), is a function of $\mathrm{x}$, the altitude above the source plane. The area under the curve, of course, is infinite.

C. Line source. A line source is very large in length yet so narrow in width that the radiation anomaly produced by it is identical to that of a theoretical "line" source, i.e., one whose width is zero. The intensity, $I_{1}(x, y, a)$, from a line source which is infinite in length, is a function of $\mathrm{x}$, the altitude of the detector above the source plane; $y$, the source plane projection of the air distance from the detector to the source center line; and $a$, the width of the source. The area under the curve recorded by a counting rate-meter, $\mathrm{H}_{1}(\mathrm{x}, \theta, a)$ is a function of $\theta$, the angle between the flight line and the plane normal to the axis of the source, as well as of ' $\mathrm{x}$ ' and ' $a$ '. (These variables are depicted in the insert to figure 14.)

D. Slab source. A slab source is so large in length that the radiation anomaly produced by it is a function of its width and independent of the length. The intensity, $I_{S}(x, y, a)$, and the area under the curve recorded by a counting rate-meter, $H_{S}(x, \theta, a)$ are functions of the same variables as for the line source. The limiting value of the slab source as $a \rightarrow 0$ is the line source. 
E. Finite source. A finite source has a circular area of radius, $a_{2}$ which is intermediate in value to the elementary and broad source. The intensity, $I_{f}\left(x_{2}, p, a\right)$, and the area under the curve recorded by a counting rate-meter, $\mathrm{H}_{f}\left(\mathrm{x}_{2} \mathrm{z}_{2} a\right)$, from a finite circular source of radius, $a_{2}$ are functions of the same variables as for the elementary source. The limiting case of the finite source as $a \rightarrow 0$ is the elementary source.

The above enumerated quantities are derived in the appendixes. All numerical computations were performed under the assumption of quarter-mile flight-line spacing and a 500-foot flight altitude.

It is shown in Appendix I, formula 9, that for a particular flight level, the intensity of a finite source, $I_{f^{g}}$ is equal to a numerical constant times the function $G_{3}\left(x_{2} \rho, a\right)$. The quantity $G_{3}(500, \rho, a)$ is tabulated in table 7 and plotted (See figure 12) for various values of "a" against " $P$ ". This plot of $G_{3}$ thus yields the relative intensities at various distances along a flight line at 500 feet above a finite source of fixed grade. The relative intensities plotted are equivalent to intensities that would be measured by a scintillation detector of short time constant in a plane flying at 500 feet above the ground along the flight line as shown in the insert to figure 12. The striking features are the rapid rise of the peak intensity with increasing radius of the source and slow increase in width of the anomaly with increasing radius. The minor variations in the slopes of the curves with major changes in radius militate against the determination of source size by slope analysis. The source ( 40 feet square by 6 inches thick) at Grand Junction, Colorado, used to establish the semi-empirical formula for an elementary source in Part I, would give rise to too low an intensity to be depicted in this figure. 
Table 7. The function $G_{3}(500, f, a)$

\begin{tabular}{|r|c|c|c|c|c|c|c|c|c|c|}
\hline$P(f t)$ & \multicolumn{7}{|c|}{$a(f t)$} \\
\hline & 400 & 500 & 600 & 700 & 800 & 900 & 1000 & 1500 & 2000 & 2500 \\
\cline { 2 - 10 } & 0.8390 & 1.0962 & 1.3147 & 1.4931 & 1.6351 & 1.7475 & 1.8354 & 2.0557 & 2.1170 & 2.1321 \\
100 & 0.7856 & 1.0558 & 1.2899 & 1.4797 & 1.6286 & 1.7445 & 1.8336 & 2.0553 & 2.1167 & 2.1318 \\
200 & 0.7152 & 0.9883 & 1.2325 & 1.4340 & 1.5935 & 1.7177 & 1.8132 & 2.0500 & 2.1153 & 2.1312 \\
300 & 0.6279 & 0.8937 & 1.1427 & 1.3560 & 1.5297 & 1.6673 & 1.7742 & 2.0398 & 2.1126 & 2.1304 \\
400 & 0.5236 & 0.7720 & 1.0203 & 1.2457 & 1.4373 & 1.5932 & 1.7165 & 2.0248 & 2.1087 & 2.1294 \\
500 & 0.4023 & 0.6232 & 0.8654 & 1.1031 & 1.3162 & 1.4954 & 1.6402 & 2.0049 & 2.1036 & 2.1281 \\
600 & 0.2962 & 0.4785 & 0.6979 & 0.9344 & 1.1637 & 1.3677 & 1.5379 & 1.9783 & 2.0964 & 2.1274 \\
700 & 0.2122 & 0.3533 & 0.5368 & 0.7543 & 0.9860 & 1.2090 & 1.4061 & 1.9416 & 2.0870 & 2.1246 \\
800 & 0.1500 & 0.2543 & 0.3977 & 0.5816 & 0.7972 & 1.0254 & 1.2437 & 1.8937 & 2.0750 & 2.1191 \\
900 & 0.1055 & 0.1806 & 0.2875 & 0.4324 & 0.6164 & 0.8306 & 1.0561 & 1.8312 & 2.0588 & 2.1160 \\
1000 & 0.0743 & 0.1277 & 0.2052 & 0.3138 & 0.4597 & 0.6438 & 0.8570 & 1.7482 & 2.0374 & 2.1138 \\
1100 & 0.0582 & 0.1001 & 0.1608 & 0.2461 & 0.3614 & 0.5084 & 0.6825 & 1.5770 & 2.0318 & 2.1010 \\
\hline
\end{tabular}


Table 7. The function $\mathrm{G}_{3}(500, \mathrm{p}, \mathrm{a})$

(Continued)

\begin{tabular}{|c|c|c|c|c|c|c|c|c|c|c|}
\hline$p(f t)$ & \multicolumn{10}{|c|}{$a(f t)$} \\
\hline & 400 & 500 & 600 & 700 & 800 & 900 & 1000 & 1500 & 2000 & 2500 \\
\hline 1200 & 0.0442 & 0.0759 & 0.1219 & 0.1867 & 0.2750 & 0.3894 & 0.5285 & 1.4098 & 2.0036 & 2.0881 \\
\hline 1300 & 0.03207 & 0.0551 & 0.0885 & 0.1357 & 0.2007 & 0.2867 & 0.3950 & 1.2466 & 1.9528 & 2.0753 \\
\hline 1500 & 0.0138 & 0.0237 & 0.0380 & 0.0586 & 0.0882 & 0.1303 & 0.1899 & 0.9320 & 1.7835 & 2.0496 \\
\hline 2000 & 0.0027 & 0.0047 & 0.0075 & 0.0116 & 0.0173 & 0.0255 & 0.0369 & 0.2150 & 0.9649 & 1.7962 \\
\hline 2500 & & & & & 0.0032 & 0.0049 & 0.0072 & 0.0426 & 0.2282 & 0.8827 \\
\hline 3000 & & & & & & & & 0.0080 & 0.0457 & 0.2362 \\
\hline 3500 & & & & & & & & & 0.0085 & 0.0478 \\
\hline 4000 & & & & & & & & & & 0.0088 \\
\hline
\end{tabular}


64

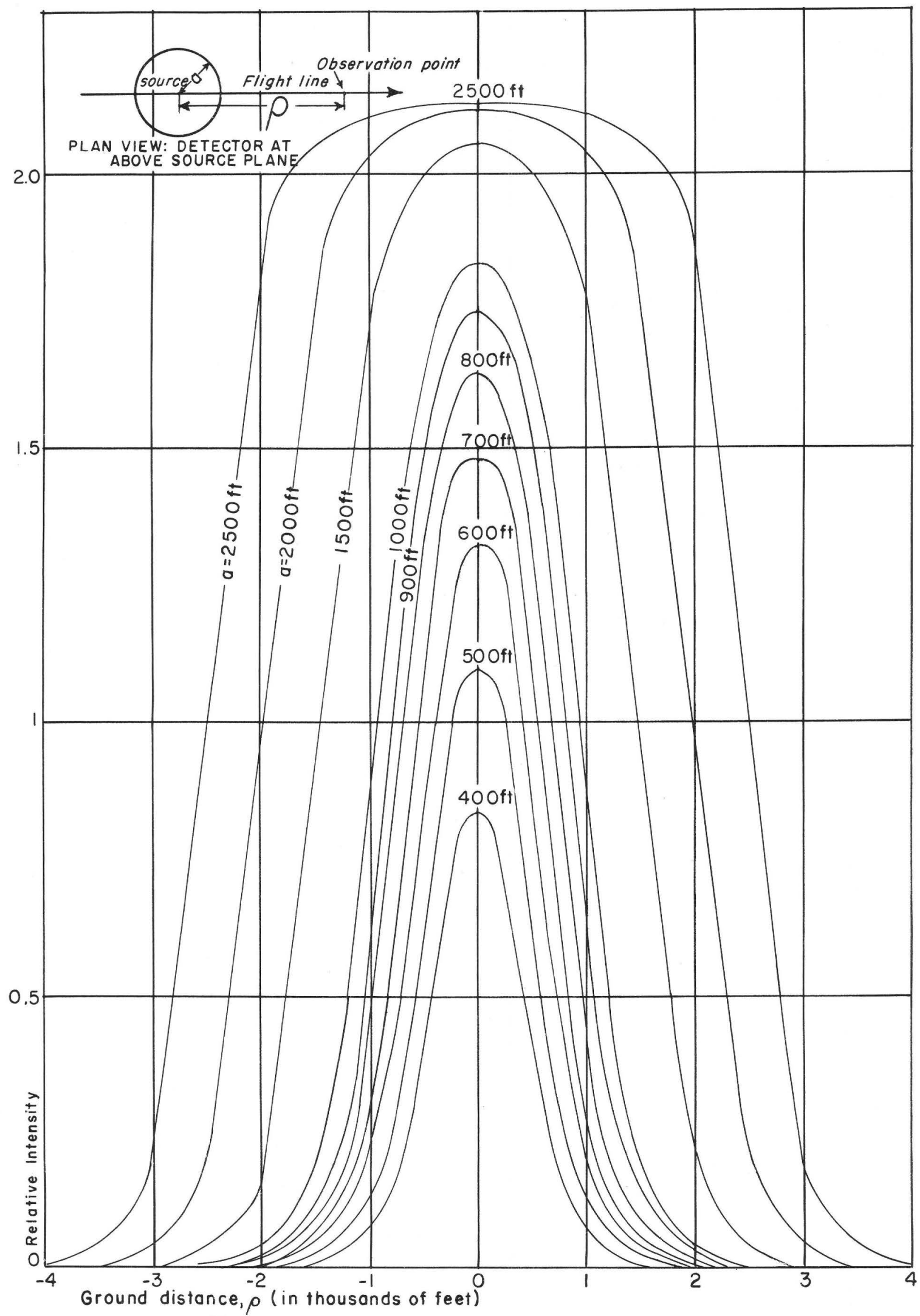

FIGURE I2-RELATIVE INTENSITIES AT VARIOUS DISTANCES FROM CENTER OF FINITE SOURCES OF VARIOUS RADII. 
Similarly, it is shown in Appendix I, formula 8 , that for a particular flight level, the intensity of a slab source, $I_{S^{2}}$ is equal to a numerical constant times the function $G_{1}\left(x_{2}, y_{9} a\right)$. The quantity $G_{1}\left(500, y_{2} a\right)$ is listed in table 8 and plotted in figure 13 for various values of ${ }^{\prime} \mathrm{a}$ ' against ${ }^{\mathrm{P}} \mathrm{y}$, yielding the relative intensities at various distances, $y_{2}$ along the flight line at 500 feet above slab sources of various sizes and of the same grade. The curves are equivalent to profiles of anomalies that would be obtained under normal airborne surveying conditions. Again, slope analysis to determine source size is not feasible。

In figure 14 , the relative intensities at 500 feet above a slab source 400 feet in width are plotted as a function of $y^{p}$, the ground projection of the air distance along the flight line from the detector to the center line of the source, where the individual curves are plotted for various angles of approach between the flight line and the center line of the source. The effect of oblique angles of approach completely invalidates any attempts at slope analysis.

The impossibility of slope analysis is further illustrated in figure 15, where the relative intensities from finite sources of 400and 500-feet radius are plotted against $y_{9}$ the distance along the flight line at 500 feet above the source plane, where the closest distance from the flight line to the source center is given by its ground projection, $z_{2}$ as shown in the insert. These curves can also be considered as identical with anomalies that would be actually recorded on these flight lines. The shapes are strongly dependent on the distance of the flight line from the source center. 
Table 8. The function $G_{I}(500, y, a)$.

\begin{tabular}{|c|c|c|c|c|c|c|c|c|c|c|}
\hline \multirow{2}{*}{$y(f t)$} & \multicolumn{4}{|l|}{$=$} & \multicolumn{2}{|c|}{$a(f t)$} & \multirow[b]{2}{*}{1000} & \multirow[b]{2}{*}{1500} & \multirow[b]{2}{*}{2000} & \multirow[b]{2}{*}{2500} \\
\hline & 400 & 500 & 600 & 700 & 800 & 900 & & & & \\
\hline 0 & 0.8086 & 0.9780 & 1.1303 & 1.2655 & 1.3843 & 1.4879 & 1. 5778 & 1.8720 & 2.0098 & 2.0727 \\
\hline 400 & 0.4569 & 0.5784 & 0.7027 & 0.8287 & 0.9543 & 1.0773 & 1.1955 & 1.6602 & 1.9095 & 2.0263 \\
\hline 500 & 0.3496 & 0.4470 & 0.5500 & 0.6584 & 0.7715 & 0.8877 & 1.0051 & 1.5267 & 1.8422 & 1.9966 \\
\hline 600 & 0.2621 & 0.3372 & 0.4183 & 0.5061 & 0.6007 & 0.7021 & 0.8091 & 1.3569 & 1.7489 & 1.9532 \\
\hline 700 & 0.1946 & 0.2511 & 0.3129 & 0.3809 & 0.4559 & 0.5384 & 0.6286 & 1.1583 & 1.6246 & 1.8909 \\
\hline 800 & 0.1439 & 0.1859 & 0.2322 & 0.2835 & 0.3408 & 0.4049 & 0.4766 & 0.9478 & 1.4657 & 1.8076 \\
\hline 900 & 0.1063 & 0.1375 & 0.1718 & 0.2100 & 0.2529 & 0.3013 & 0.3562 & 0.7466 & 1.2748 & 1.6976 \\
\hline 1000 & 0.0787 & 0.1017 & 0.1270 & 0.1553 & 0.1871 & 0.2232 & 0.2643 & 0.5714 & 1.0638 & 1.5543 \\
\hline 1500 & 0.0177 & 0.0228 & 0.0284 & 0.0347 & 0.0417 & 0.0496 & 0.0587 & 0.1291 & 0.2767 & 0.5766 \\
\hline 2000 & 0.0036 & 0.0047 & 0.0059 & 0.0072 & 0.0087 & 0.0104 & 0.0124 & 0.0279 & 0.0604 & 0.1292 \\
\hline 2500 & & & & & 0.0010 & 0.0013 & 0.0017 & 0.0048 & 0.0118 & 0.0271 \\
\hline 3000 & & & & & & & & & & 0.0041 \\
\hline
\end{tabular}


67

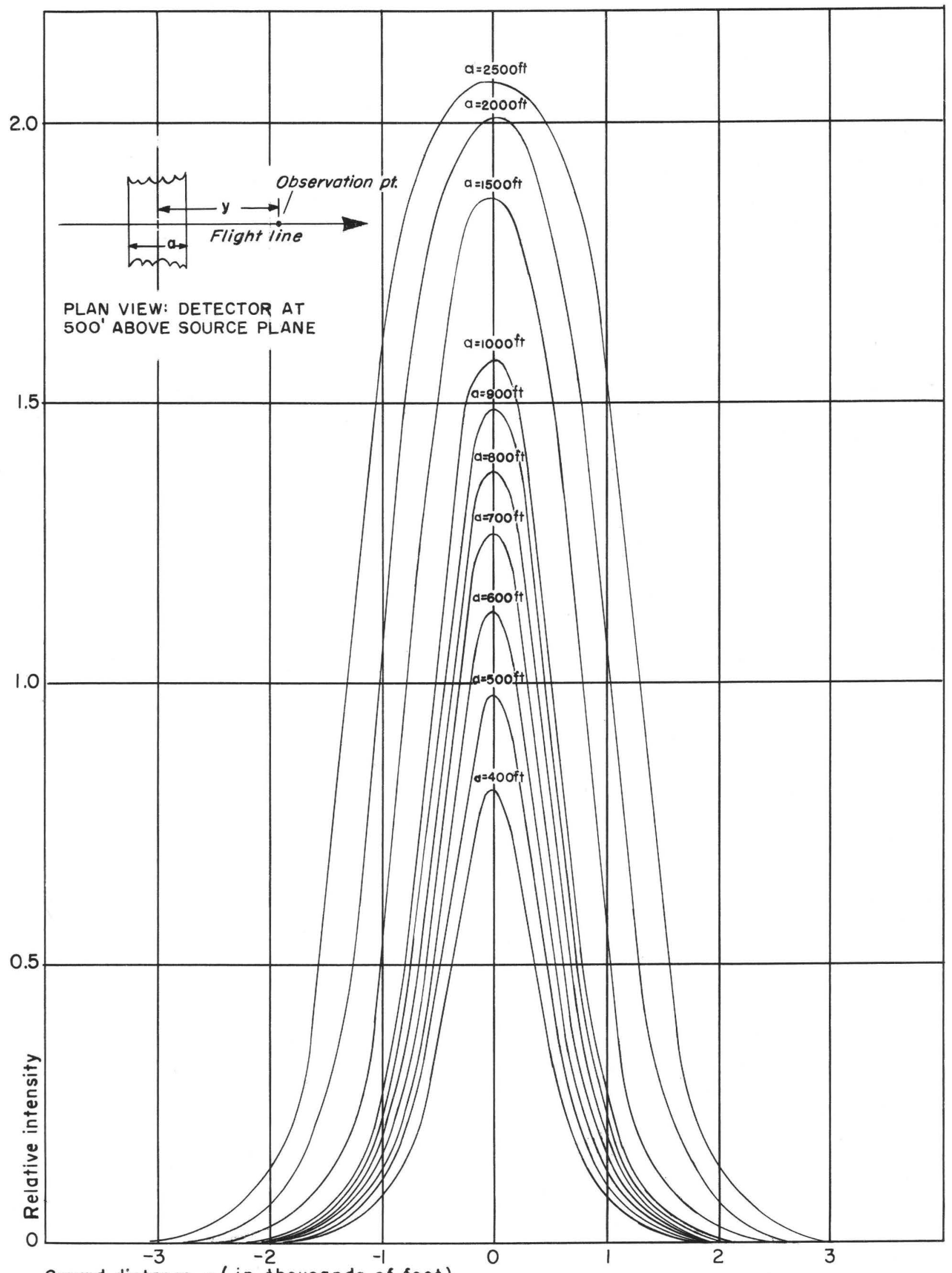

Ground distance, $y$ ( in thousands of feet)

FIGURE I3 - RELATIVE INTENSITIES AT VARIOUS DISTANCES FROM CENTER LINE OF SLAB SOURCES OF VARIOUS WIDTHS 


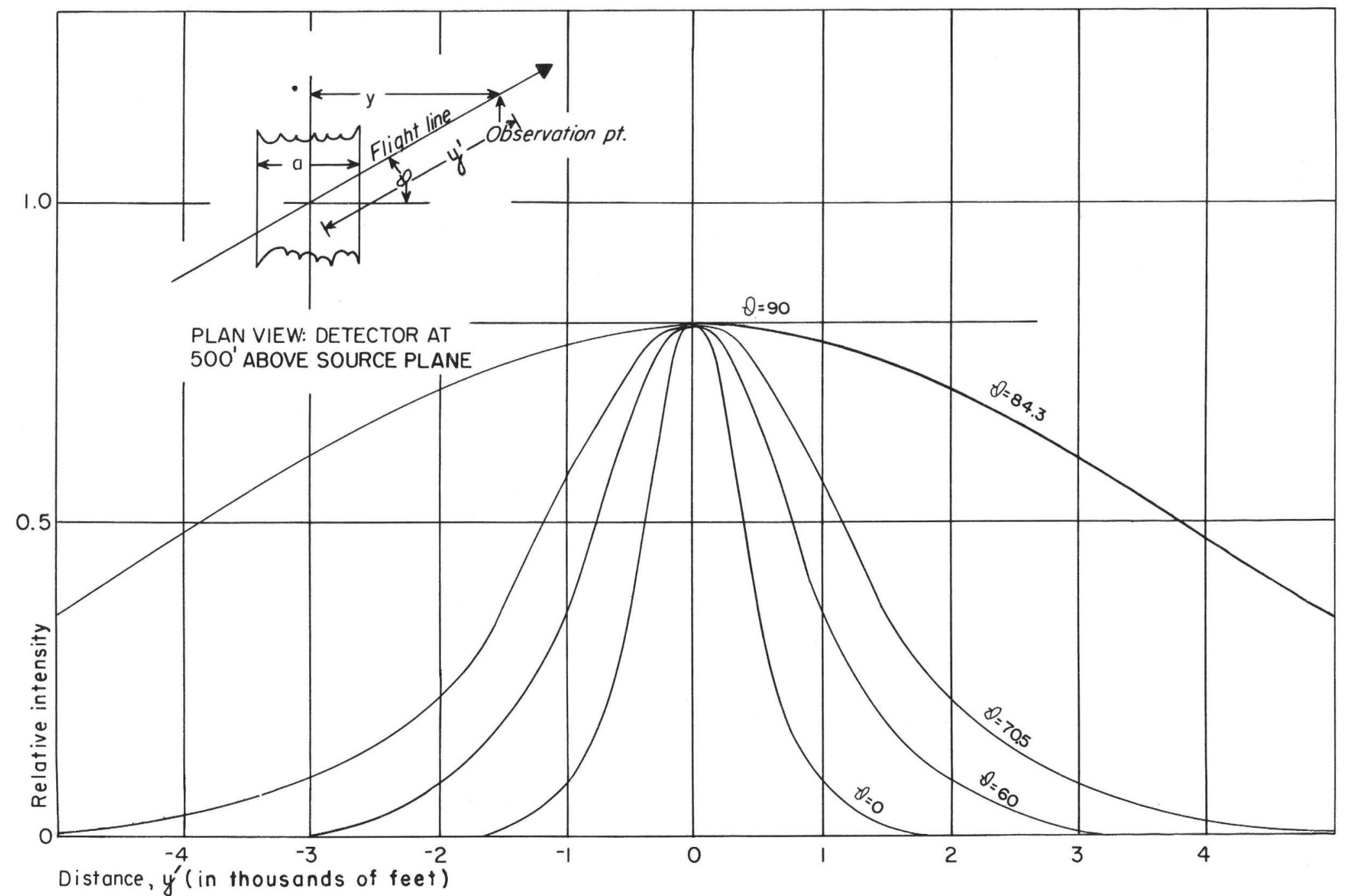

$\stackrel{\infty}{\infty}$

FIGURE I4-RELATIVE INTENSITIES AT VARIOUS DISTANCES FROM CENTER LINE OF A SLAB SOURCE $400 \mathrm{FT}$ WIDE AT VARIOUS ANGLES OF APPROACH 
6.9

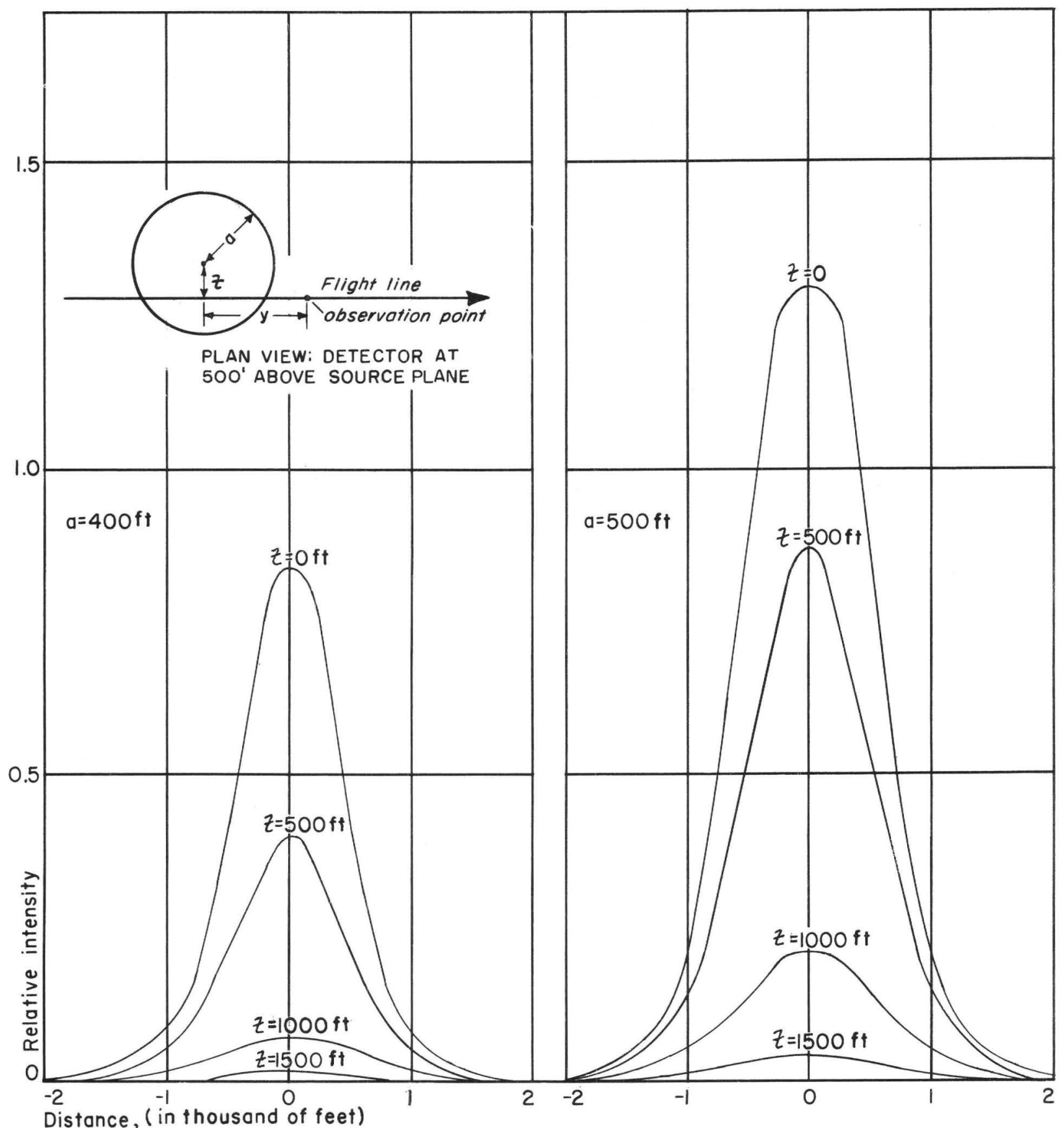

FIGURE I5-RELATIVE INTENSITIES AT VARIOUS DISTANCES ALONG

FLIGHT LINE AT VARIOUS DISTANCES FROM CENTER OF FINITE SOURCES OF $400 \mathrm{FT}$ AND $500 \mathrm{FT}$ RADII. 
Examination of figure 16 reveals another difficulty in utilizing the shape of anomalies to determine their sizes. One cannot, in general, say that the point where the intensity drops to a certain fraction of the peak intensity is the edge of the source, for the intensity ratio at the edge to that of the center is one for zero radius (width) and asymptotically approaches one-half for an infinite radius (width). The limiting values are easy to understand: for zero radius (width), the edge and the center are the same point; whereas for the infinite radius (width), the point at the edge corresponds to slicing away exactly one-half of an infinite source. Because of the rapid variation of the ratio at small source dimensions, boundary identification by this method is impossible, but for broad sources, the one-half intensity point yields the source boundary. 
71

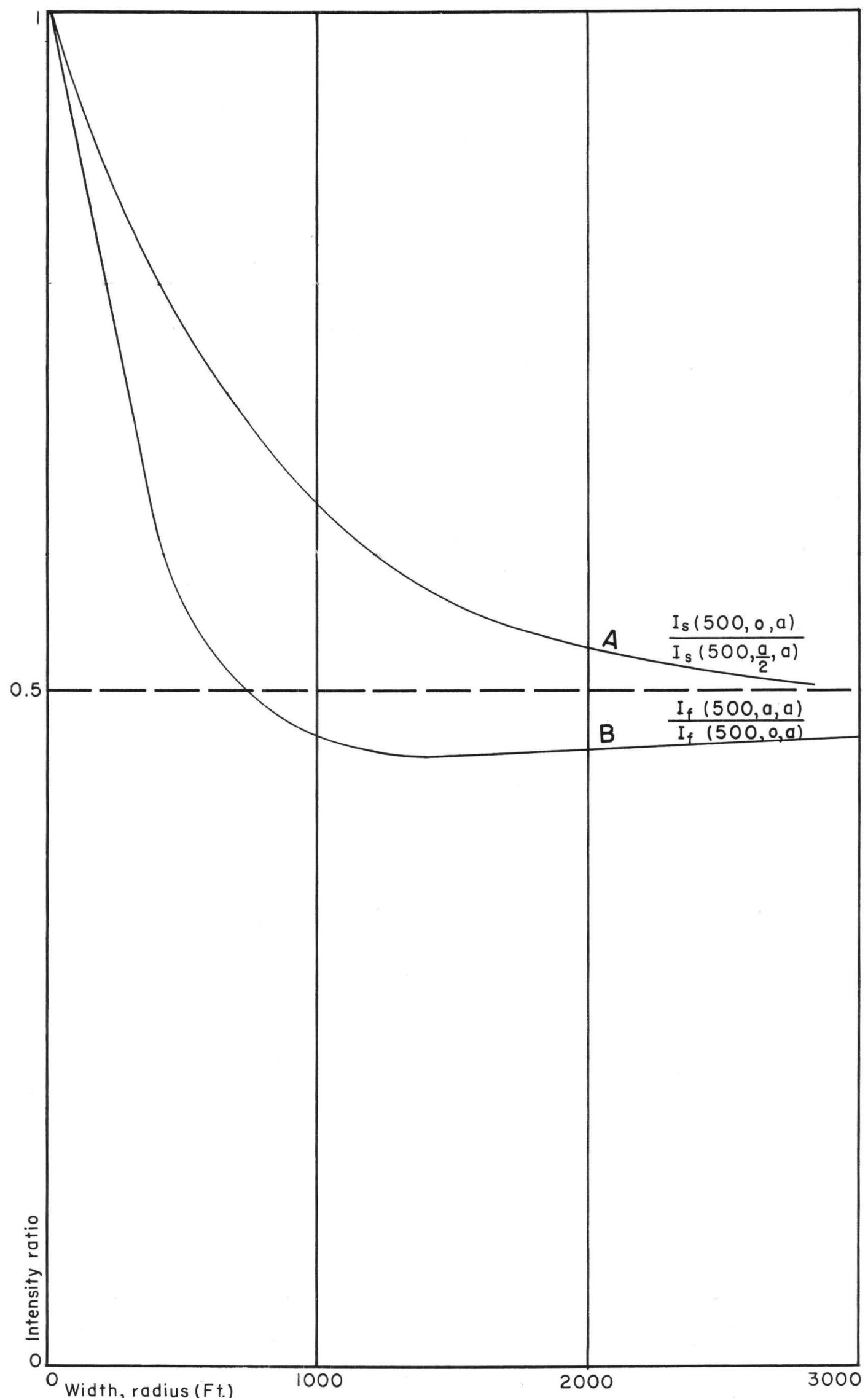

FIGURE 16-RATIO OF INTENSITY AT EDGE TO INTENSITY AT CENTER OF SOURCE. (A) .SLAB SOURCE INTENSITY RATIOS VS. WIDTH. (B). FINITE SOURCE INTENSITY RATIO VS. RADIUS 
In figure 17, curves $A$ and $B$ answer the question "How infinite is infinity?" or what is the upper limit of the size of a finite or slab source required so that for a point centrally located 500 feet above the source, the intensity is essentially equivalent to that from an infinite broad source. Curves A and B show (as a function of increasing radius or width) the ratio of the intensities from a finite and slab source respectively to the intensity of an infinite broad source. If it is assumed that for practical purposes 80 percent of the intensity from an infinite broad source would be indistinguishable from the intensity (or behavior) of an infinite broad source, then a finite or a slab source with a radius greater than 850 feet or a width greater that 1,200 feet respectively could be considered an infinite source. Curves A and B are plots of expression (9) and (8) at ' $p$ ' and ' $\mathrm{y}$ ': set equal to zero, both divided by expression (2), where ' $x$ ' in all cases is 500 feet (see expressions (1), (8), (9) in Appendix I); thus, the curves are applicable only to measurements made at 500 feet above the source plane. 


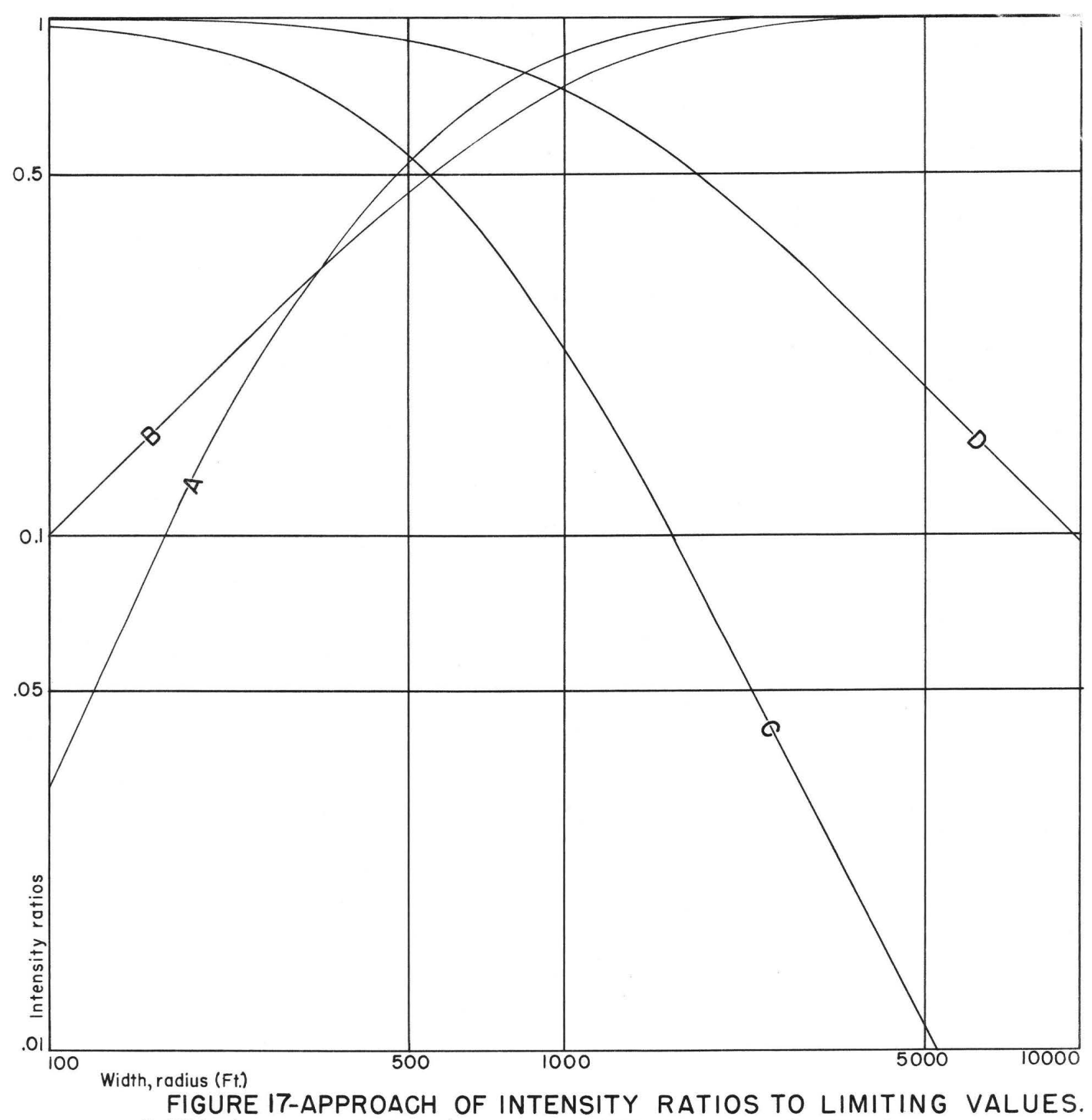

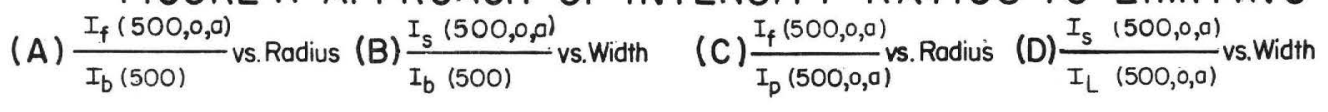


Curve $C$ in figure 17 shows the ratio of the intensity from a finite source to that from an elementary (point) source and thus indicates the lower limit of size of a finite source where the finite source intensity would be essentially identical to that from an elementary source. Again if it is assumed for practical purposes that 80 percent of the intensity from an elementary source would be indistinguishable from the intensity (or behavior) of an elementary source, then a finite source with a radius less than 275 feet can be considered an elementary source. Curve $C$ is a plot of expression (9) divided by expression (1), at ' $p$ ' set equal to zero and ${ }^{\prime} \mathrm{x}$ ' set at 500 feet (see expression (1) and (9) in Appendix I)。

Curve $D$ in figure 17 shows the ratio of the intensity from a slab source to that from a line source and indicates the lower limit of size where the slab source intensity would be essentially identical to that from a line source. Again, if it is assumed for practical purposes that 80 percent of the intensity from a line source would be indistinguishable from the intensity (or behavior) of a line source, then a slab source with a width less than 800 feet can be considered a line source. Curve D is a plot of expression ( 8 ) divided by expression (4), where ' $y$ ' is zero and ${ }^{\prime} \mathrm{x}$ ' is 500 feet (see expressions (4) and ( 8 ) in Appendix I). 
For the specific radiation detection equipment currently used by the U. S. Geological Survey, the minimum detectable increase in counting rate is approximately 50 counts per second, equivalent to twice the standard deviation of measurement. Figure 18 shows the grade $\left(\mathrm{eU}_{3} \mathrm{O}_{8}\right)$ of finite sources of various radii that would be detectable at a $500-$ foot altitude of flight lines directly over, 600 feet away, and 1,300 feet away from the source center. Curve A gives the most unfavorable case in which the flight line is at a horizontal distance of 1,300 feet from the source center. Even then, an ore-grade body (more than 0.1 percent equivalent uranium) with a minimum radius of 200 feet is detectable on two adjacent flight lines spaced at 1,300 feet (I/4-mile) apart. Curves $B$ and $C$ are for the flight lines 600 and 0 feet away, and give correspondingly lower radii. Taking the 600-foot distance to be the most likely case, an ore grade body with a minimum radius of 600 feet located midway between flight lines spaced at 1,300 feet can be detected.

\section{RELATIONSHIP OF OBSERVABLE DATA TO SOURCE CHARACTERISTICS}

The general behavior of the radiation intensities from natural sources discussed above indicates that the useful observable quantities are the peak intensity, $I$, and the area under the curve, $H_{0}$ The third readily apparent observable quantity, the shape of an anomaly as characterized by the slope or by the width at half-manimum intensity, has been demonstrated to be of little value for interpretation of source characteristics. 


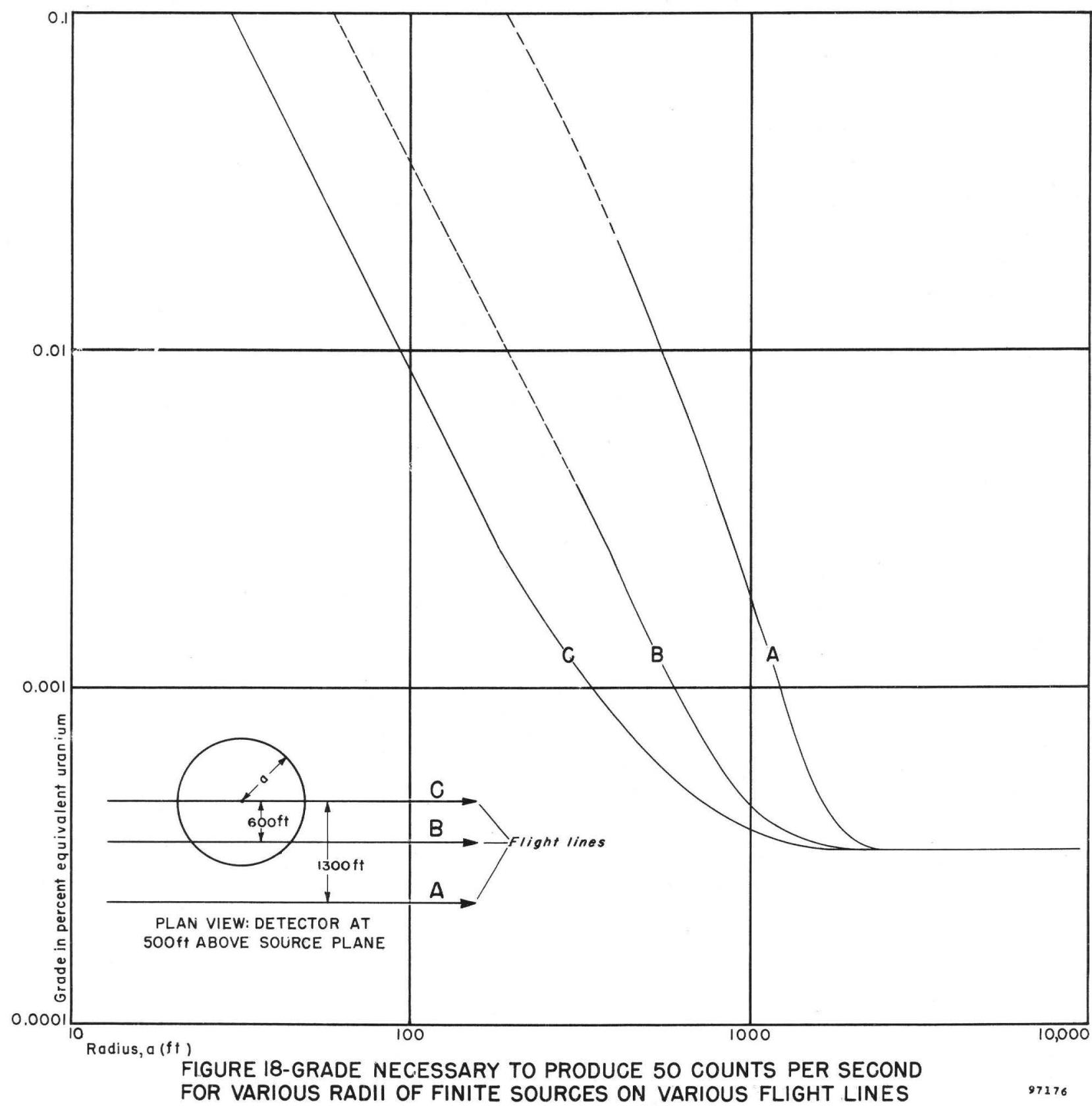


A plot (figure 19) of $G_{4}\left(500, z_{9} a\right)$ of table 9 against $G_{3}(500, z, a)$ of table $I$ corresponds to a plot of arbitrarily scaled $\mathrm{H}_{f}(500, \mathrm{z}, \mathrm{a})$ against arbitrarily scaled $I_{f}(500, \rho, a)$, at the points where ' $\rho$ ' equals $' z^{p}$, the ground projection of the air distance of closest approach to the source center. This can be seen by dividing equation (9), Appendix I by equation (7), Appendix II to form $G_{3} / G_{4}=2 I_{f} / H_{f}$. It is obvious that these plots are of little practical use as the scaling factors for real anomalies are unknown. However, by considering the graph, the following relationship is suggested.

$$
G_{4}(500, z, a)=F(a)\left[G_{3}(500, z, a)\right]^{\alpha}
$$

where $F(a)$ is a function of ' $a$ '. Now for the case of small ' $a$ ', the finite source reduces to an elementary source, and from expressions (1) and (9) of Appendix I and expressions (3) and (7) of Appendix II, the functions $G_{3}(500, z, a)$ and $G_{4}(500, z, a)$ can be readily computed for small ' $a$ '. Then, assuming the form of expression $I$, and fitting the expression to the computed values, by the method of least squares, it is found that

$$
G_{4}(500, z, a) \frac{a^{-2}}{500}=\underset{a \rightarrow 0}{2.18}\left[G_{3}(500, z, a)\left(\frac{a}{500}\right)^{-2}\right]^{0.788}
$$

upon application of expressions (9) of Appendix I and (7) of II; the above equation becomes

$$
\frac{H_{f}(500, z, a)}{\frac{4 C S}{S_{0} A_{0}}\left(500 \mu_{0}\right) \frac{a^{2}}{500}}=2.18\left[\frac{I_{f}\left(500, z_{, a} a\right.}{\left(\frac{a}{500}\right)^{2} \frac{2 C S}{S_{0} A_{0}} 500 \mu_{0}}\right]^{0.788}
$$




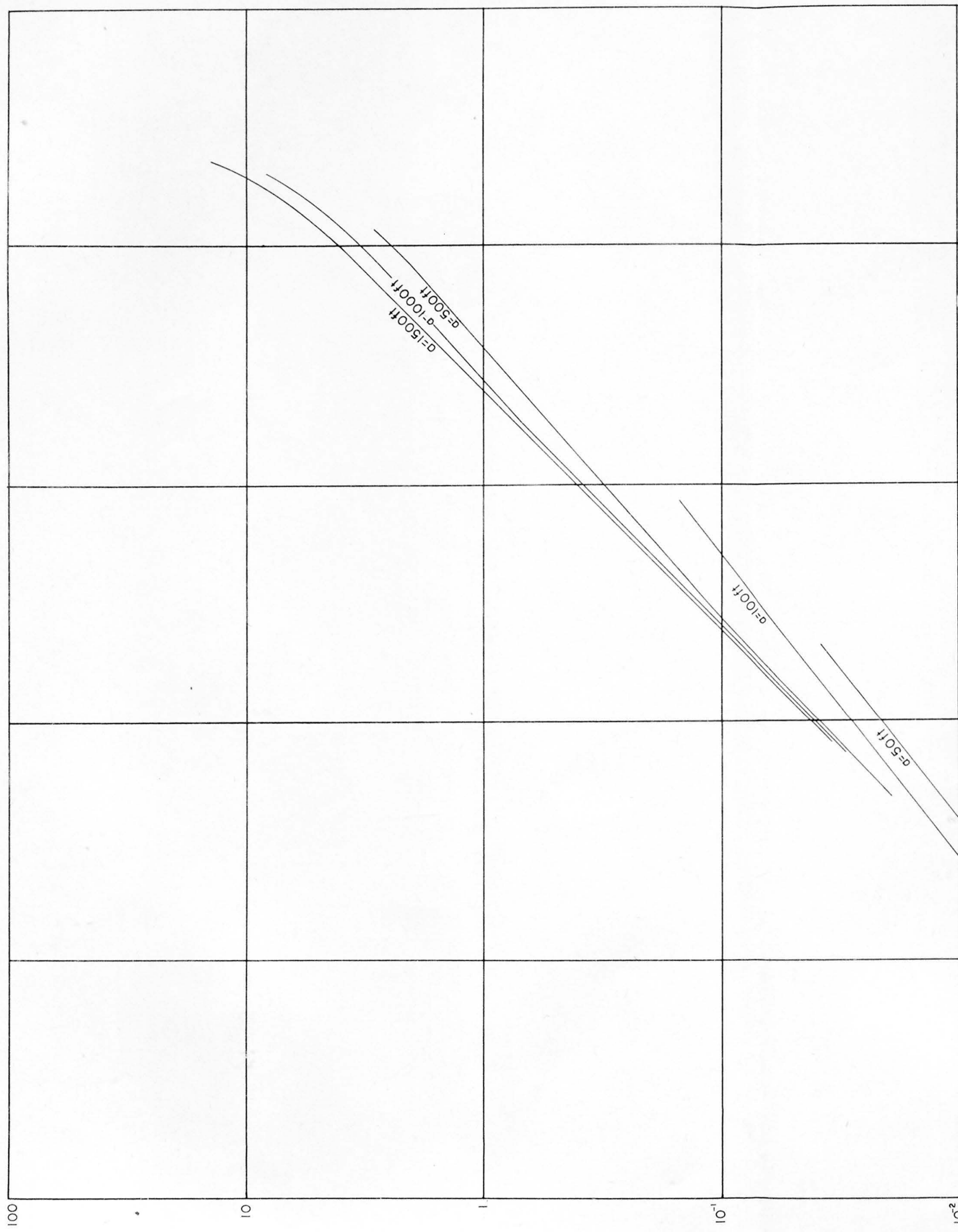


Table 9. The function $G_{4}(500, z, a)$

\begin{tabular}{|r|c|c|c|c|c|c|c|c|c|c|}
\hline$z(f t)$ & \multicolumn{7}{|c|}{$a(f t)$} \\
\hline & 400 & 500 & 600 & 700 & 800 & 900 & 1000 & 1500 & 2000 & 2500 \\
\hline 0 & 2.0395 & 2.9588 & 3.9346 & 4.9385 & 5.9824 & 7.0540 & 8.1419 & 13.1905 & 18.1905 & 23.0945 \\
100 & 1.9134 & 2.8337 & 3.8268 & 4.8469 & 5.9096 & 6.9872 & 8.0807 & 13.1576 & 18.3635 & 23.0731 \\
200 & 1.7513 & 2.6455 & 3.6313 & 4.6534 & 5.7248 & 6.8081 & 7.9094 & 13.0481 & 18.2865 & 23.0079 \\
300 & 1.5530 & 2.3941 & 3.3480 & 4.3579 & 5.4279 & 6.5168 & 7.6279 & 12.8622 & 18.1511 & 22.8988 \\
400 & 1.3186 & 2.0796 & 2.9770 & 3.9605 & 5.0191 & 6.1133 & 7.2363 & 12.5997 & 17.9573 & 22.7459 \\
500 & 1.0481 & 1.7019 & 2.5182 & 3.4611 & 4.4983 & 5.5975 & 6.7345 & 12.2607 & 17.7051 & 22.5491 \\
600 & 0.8049 & 1.3398 & 2.0450 & 2.9096 & 3.9037 & 4.9849 & 6.1324 & 11.8380 & 17.3894 & 22.3036 \\
700 & 0.6063 & 1.0241 & 1.6010 & 2.3549 & 3.2663 & 4.3063 & 5.4361 & 11.3264 & 17.0114 & 22.0047 \\
800 & 0.4509 & 0.7709 & 1.2224 & 1.8406 & 2.6318 & 3.5872 & 4.6735 & 10.7206 & 16.5624 & 21.6649 \\
900 & 0.3343 & 0.5745 & 0.9211 & 1.4029 & 2.0571 & 2.8886 & 3.8868 & 10.0076 & 16.0254 & 21.2993 \\
1000 & 0.2475 & 0.4261 & 0.6857 & 1.0496 & 1.5667 & 2.2501 & 3.1170 & 9.1951 & 15.4124 & 20.8783 \\
1100 & 0.1972 & 0.3393 & 0.5461 & 0.8364 & 1.2496 & 1.7994 & 2.5058 & 8.0093 & 14.6867 & 20.4541 \\
1200 & 0.1529 & 0.2627 & 0.4230 & 0.6484 & 0.9699 & 1.4014 & 1.9648 & 6.9047 & 13.8871 & 19.9409 \\
1300 & 0.1144 & 0.1964 & 0.3164 & 0.4856 & 0.7275 & 1.0561 & 1.4940 & 5,8811 & 13.0136 & 19.3386 \\
\hline
\end{tabular}


Table 9. The function $\mathrm{G}_{4}(500, \mathrm{z}, \mathrm{a})$--continued

\begin{tabular}{|c|c|c|c|c|c|c|c|c|c|c|}
\hline \multirow[b]{2}{*}{$z(f t)$} & \multicolumn{10}{|c|}{$a(f t)$} \\
\hline & 400 & 500 & 600 & 700 & 800 & 900 & 1000 & 1500 & 2000 & 2500 \\
\hline 1500 & 0.0554 & 0.0946 & 0.1527 & 0.2354 & 0.3547 & 0.5234 & 0.7632 & 4.0773 & 11.0450 & 17.8670 \\
\hline 2000 & 0.0116 & 0.0198 & 0.0323 & 0.0505 & 0.0764 & 0.1133 & 0.1658 & 0.9870 & 4.8304 & 12.6298 \\
\hline 2500 & & & & & 0.0123 & 0.0202 & 0.0308 & 0.2091 & 1.1628 & 5.4713 \\
\hline 3000 & & & & & & & & 0.0348 & 0.2425 & 1.3130 \\
\hline 3500 & & & & & & & & & 0.0382 & 0.2728 \\
\hline 4000 & & & & & & & & & & 0.0420 \\
\hline
\end{tabular}


Thus, the grade-area, $S \pi a^{2}=S A$,

$$
S A=\left[\frac{S_{0} A_{0} 500 \pi}{2 C_{0}}\right]\left[\frac{H_{f}(500, z, a)}{4.36\left\{I_{f}(500, z, a)\right\} 0.788}\right] \frac{I}{0.212}
$$

Thus, two transcendental equations, (I) of Appendix I and (3) of Appendix II, in two unknowns, ' $z$ ' and 'SA', were solved empirically to give explicit expression for grade-area for any value of ' $z$ ', in terms of the two observed quantities, $H_{f}(500, z, a)$ and $I_{f}(500, z, a)$. Expression (4) is true for elementary sources and approximately true for finite sources.

From tabulated values of $G_{3}(500, z, a)$ and $G_{4}(500, z, a)$ and from expressions (9) of Appendix I and (7) of Appendix II, insertion into expression (4) yields incorrect grade-area for a finite source. The ratio of this incorrect value to the true value of grade-area is listed in table 10, as a function of ${ }^{\prime} z^{\prime}$ and ' $a$ '. One notes that the range in values is considerable. However, for any fixed 'a', the arithmetic mean of the grade-area ratios calculated at ${ }^{8} z^{8}$ and at $1300-z$ (average of ratios over two flight lines straddling the source center) is reasonably constant as shown in table 1l. The arithmetic mean at a fixed radius of the reciprocals of the values in table 6 is taken, and these average values are listed in table 12 along with maximum and minimum values of the reciprocals at a fixed ' $a$ '. Thus, if the approximate surface dimension of the source were known, application of equation (4) followed by multiplication by the proper correction factor in table 12 should yield the correct grade-area of finite sources. The tabulated extreme values in table 12 indicates that the error in source location entails only 15 percent error in the correction factor. 
Table 10. Ratio of grade-area predicted from point source relation to actual grade-area as function of radius, $a$, and ground projection, $z$, of closest distance of approach.

\begin{tabular}{|c|c|c|c|c|c|c|c|}
\hline \multirow[b]{2}{*}{$(f t)$} & \multicolumn{7}{|c|}{$a(f t)$} \\
\hline & 400 & 500 & 600 & 700 & 800 & 900 & 1000 \\
\hline 0 & 2.32 & 2.98 & 4.08 & $5 \cdot 46$ & 7.34 & 9.78 & 13.10 \\
\hline 100 & 2.04 & 2.82 & 3.85 & 5.50 & 7.07 & $9 \cdot 42$ & 12.60 \\
\hline 200 & 1.91 & 2.61 & 3.56 & 4.80 & 6.56 & 8.89 & 12.00 \\
\hline 300 & 1.76 & 2.36 & 3.19 & $4 \cdot 34$ & 5.98 & 8.09 & 11.00 \\
\hline 400 & 1.61 & 2.10 & 2.82 & 3.78 & 5.20 & 7.01 & 9.65 \\
\hline 500 & 1.55 & 1.80 & 2.36 & 3.15 & $4 \cdot 26$ & 5.62 & 8.13 \\
\hline 600 & 1.29 & 1.55 & 1.95 & 2.58 & 3.48 & 4.78 & 6.73 \\
\hline 700 & 1.18 & 1.37 & 1.65 & 2.11 & 2.79 & 3.80 & 5.25 \\
\hline 800 & 1.06 & 1.21 & 1.39 & 1.73 & 2.22 & 2.82 & $4 \cdot 10$ \\
\hline 900 & 0.945 & 1.07 & 1.22 & 1.45 & 1.81 & 2.31 & 3.13 \\
\hline 1000 & 0.877 & 0.994 & 1.08 & 1.22 & 1.48 & 1.84 & 2.40 \\
\hline 1100 & 0.672 & 0.808 & 0.904 & 1.01 & 1.25 & 1.54 & 2.00 \\
\hline 1200 & 0.627 & 0.685 & 0.788 & 0.867 & 1.04 & 1.29 & 1.84 \\
\hline 1300 & 0.494 & 0.559 & 0.634 & 0.724 & 0.852 & 1.05 & 1.34 \\
\hline
\end{tabular}


Table 11. Ratio of point source grade-aréa to actual grade-area averaged over two flight lines as function of radius, a, and ground projection, $\mathrm{z}$, of closest distance of approach.

\begin{tabular}{|r|r|l|l|l|l|l|l|}
\hline & \multicolumn{7}{|c|}{$a(f t)$} \\
\cline { 2 - 7 }$z(f t)$ & 400 & 500 & 600 & 700 & 800 & 900 & 1000 \\
\hline 0 & 1.40 & 1.76 & 2.35 & 3.09 & 4.09 & 5.41 & 7.20 \\
100 & 1.38 & 1.75 & 2.32 & 3.01 & 4.05 & 5.35 & 7.20 \\
200 & 1.29 & 1.71 & 2.23 & 2.91 & 3.91 & 5.16 & 7.00 \\
300 & 1.32 & 1.72 & 2.13 & 2.78 & 3.73 & 4.96 & 6.70 \\
400 & 1.24 & 1.58 & 2.02 & 2.61 & 3.50 & 4.66 & 6.39 \\
500 & 1.30 & 1.50 & 1.88 & 2.44 & 3.24 & 4.22 & 6.11 \\
600 & 1.23 & 1.46 & 1.85 & 2.35 & 3.13 & 4.29 & 5.99 \\
\hline
\end{tabular}




\section{4}

Table 12. Conversion factors to correct point source grade-area prediction to true grade-area for finite sources. Minimum and maximum columns show extreme spread in factors.

\begin{tabular}{|c|c|c|c|}
\hline$a(f t)$ & Minimum & Average & Maximum \\
\hline 0 & 1.000 & 1.000 & 1.000 \\
400 & .714 & .765 & .813 \\
500 & .568 & .613 & .684 \\
600 & .426 & .477 & .540 \\
700 & .324 & .368 & .425 \\
800 & .244 & .276 & .319 \\
900 & .185 & .207 & .233 \\
1000 & .139 & .151 & .167 \\
\hline
\end{tabular}


It remains now to determine the radius of the finite source. A useful grade independent quantity is $\mathrm{H}_{f}\left(500, \mathrm{z}_{a} a\right)$ which is tabulated in $\frac{1}{I_{f}(500, z, a)}$

table 13.' In figure 20, the data in table 13 at ' $z^{\prime}$ is plotted against the quantity at $1300-/ z$ for various values of ${ }^{\prime} a q^{2}$ a comparison of data from two adjacent flight lines straddling the sounce. The solid curve represents a given source radius; the dotted curves connect constant ground distances from the nearer flight line to the source-(z). To get grade-area, one can get the radius of the source and closest distance of approach from this plot and apply a correction from the proper entry in table 10 to the computed value from equation (4). However, a ten percent error in $\mathrm{H}$ and $I$ would result in an error of the ratio $H / I$, represented by the grid length in figure 20. This could result in a possible error in "z" by as much as 600 feet and an error in "a" by 200 feet. The variation with distance, $z_{g}$ of predicted to true grade-area ratios at a given radius is quite serious, as an examination of table 10 will show. Thus, it is better to estimate by figure 20 what the radius is, to compute the grade-area on two adjoining lines through equation (4), and to apply the proper correction factor in table 12. With grade-area and radius known, it would be easy to find the grade.

For slab sources table 14 furnishes the quantity, $\frac{H_{S}(500,0, a)}{I_{S}(500,0, a)}$ which is plotted in figure 21 as function of the slab width, a. These grade-independent quantities can be used to estimate the width of the slab source. Once the width is determined, the grade can be determined from expression (8) of Appendix I with ' $\mathrm{y}$ ' set equal to zero. 
Table 13. Ratio of total counts, $H_{f}(500, z, a)$, to peak intensity, $I_{f}(500, z, a)$, as function of radius, a, and ground projection, $z$, of the closest distance of approach for finite source.

\begin{tabular}{|c|c|c|c|c|c|c|c|c|}
\hline \multirow[b]{2}{*}{$z(f t)$} & \multicolumn{8}{|c|}{$a(f t)$} \\
\hline & 0 & 400 & 500 & 600 & 700 & 800 & 900 & 1000 \\
\hline 0 & 3.74 & 4.86 & $5 \cdot 40$ & 5.99 & 6.62 & 7.32 & 8.07 & 8.87 \\
\hline 100 & 3.76 & 4.70 & 5.37 & 5.93 & 6.55 & 7.26 & 8.01 & 8.81 \\
\hline 200 & 3.93 & $4 \cdot 90$ & 5.35 & 5.89 & 6.49 & 7.19 & 7.93 & 8.72 \\
\hline 300 & $4 \cdot 16$ & 4.95 & 5.36 & 5.86 & 6.43 & 7.10 & 7.80 & 8.60 \\
\hline 400 & 4.51 & 5.04 & 5.39 & 5.84 & 6.36 & 6.98 & 7.67 & 8.43 \\
\hline 500 & 4.89 & 5.21 & 5.46 & 5.82 & 6.28 & 6.84 & 7.49 & 8.21 \\
\hline 600 & 5.22 & 5.43 & 5.60 & 5.86 & 6.23 & 6.71 & 7.29 & 7.98 \\
\hline 700 & & 5.71 & 5.80 & 5.96 & 6.24 & 6.63 & 7.12 & 7.73 \\
\hline 800 & & 6.01 & 6.06 & 6.15 & 6.33 & 6.60 & 7.00 & 7.52 \\
\hline 900 & & 6.34 & 6.36 & 6.41 & 6.49 & 6.67 & 6.96 & 7.36 \\
\hline 1000 & & 6.66 & 6.67 & 6.68 & 6.69 & 6.82 & 6.99 & 7.27 \\
\hline 1100 & & 6.78 & 6.78 & 6.79 & 6.80 & 6.92 & 7.08 & 7.34 \\
\hline 1200 & & 6.92 & 6.92 & 6.94 & 6.95 & 7.05 & 7.20 & 7.44 \\
\hline 1300 & & 7.13 & 7.13 & 7.15 & 7.16 & 7.25 & $7 \cdot 37$ & 7.56 \\
\hline
\end{tabular}




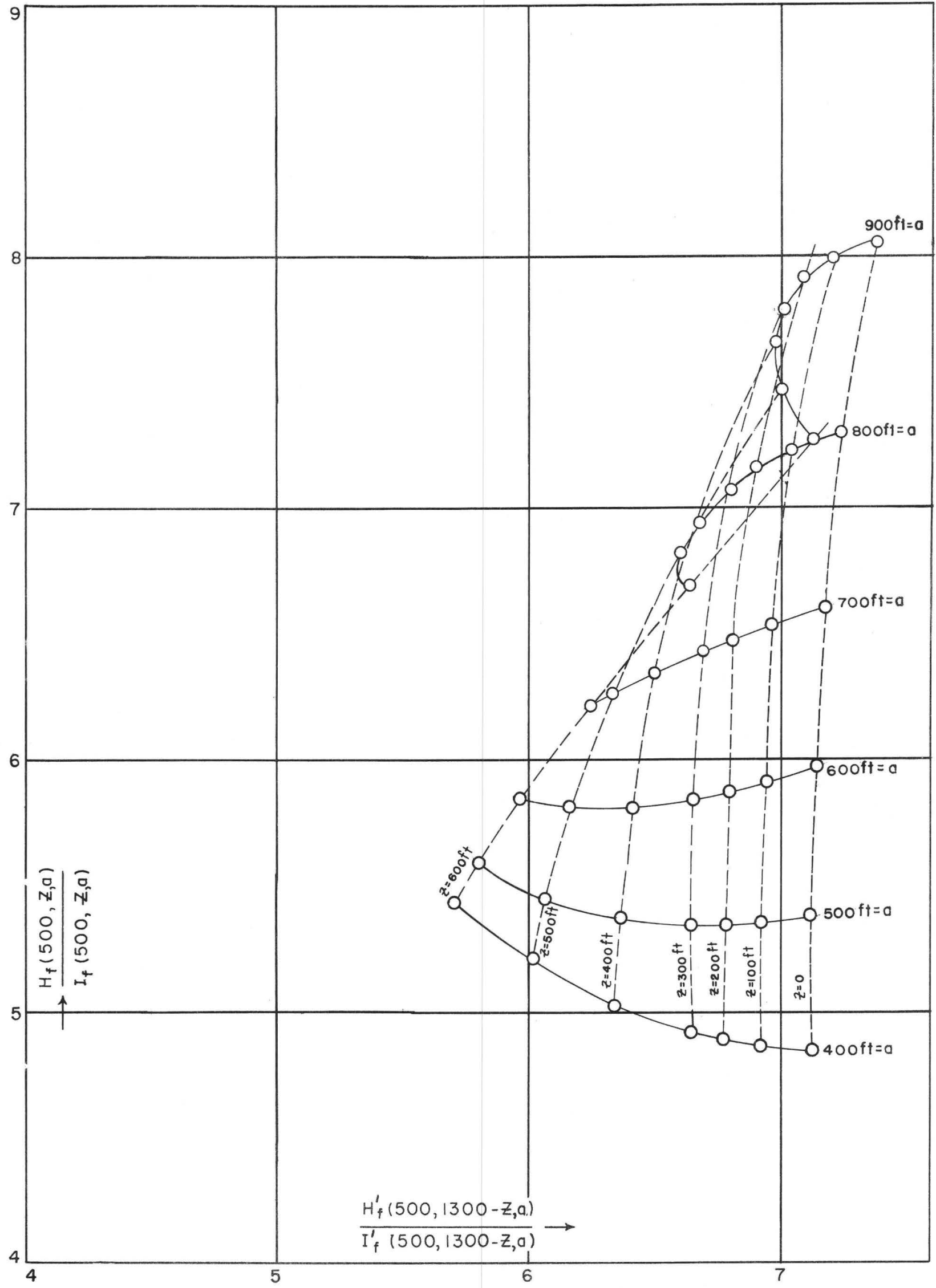

FIGURE 2O-RATIO OF AREA UNDER CURVE $\left(H_{f}\right)$ TO PEAK INTENSITY $\left(I_{f}\right)$ AT $Z$ V S. RATIO OF AREA UNDER CURVE $\left(H_{f^{\prime}}^{\prime}\right)$ TO PEAK INTENSITY $\left(I_{f}^{\prime}\right)$ AT |300-Z FOR FINITE SOURCE OF VARIOUS RADII 
Table 14. Ratio of total counts, $\mathrm{H}_{\mathrm{S}}\left(500_{2} \mathrm{O}_{2} \mathrm{a}\right)$ at normal incidence, to peak intensity, Is $\left(500, \mathrm{O}_{2} \mathrm{a}\right)$, as function of width, a, of a slab source.

\begin{tabular}{cc}
\hline a ft $)$ & $\mathrm{H}_{\mathrm{S}} / \mathrm{I}_{\mathrm{S}}$ \\
\hline $\begin{array}{c}0 \\
400\end{array}$ & 4.36 \\
500 & 4.68 \\
600 & 4.82 \\
700 & 5.02 \\
800 & 5.24 \\
900 & 5.47 \\
1000 & 5.73 \\
1500 & 6.00 \\
2000 & 7.58 \\
2500 & 0.38 \\
\hline
\end{tabular}


89

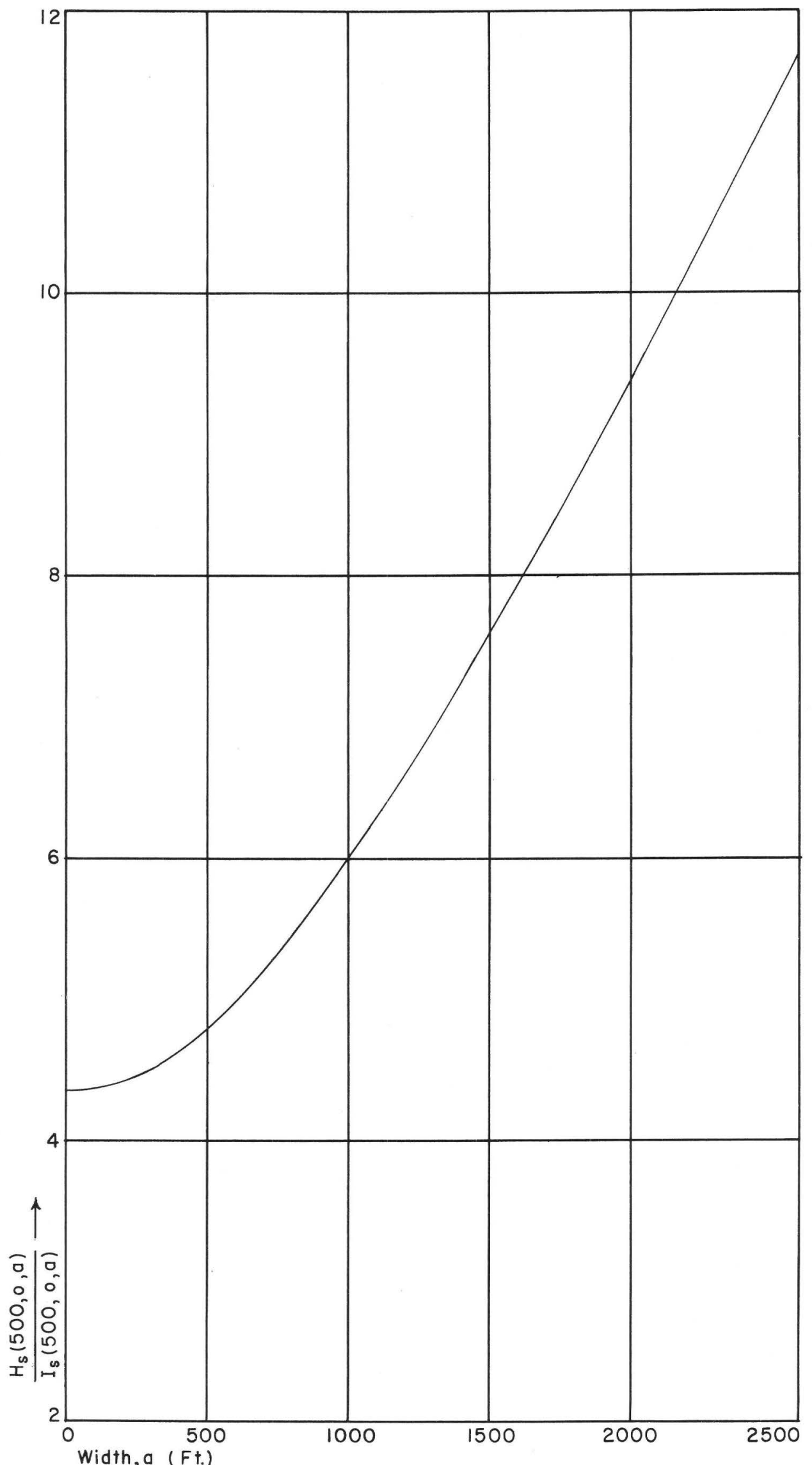

Width, a ( Ft.)

FIGURE 2I-RATIO OF AREA UNDER CURVE (Hs) TO PEAK INTENSITY (Is) VS. WIDTH OF A SLAB SOURCE AT $\varphi=0$. 


\section{INTERPRETATION OF ANOMALIES}

Based on the foregoing discussions, the" following method suggests itself。 $H$ and I represent respectively the measured area under a curve recorded on a counting rate-meter and the peak intensity reading. The procedure would be:

If the anomaly shows distinctive flattening at the peak.--The source can then be considered a broad source, and the grade computed from expression (2) of Appendix I. The boundary of the source is at the onehalf peak intensity point.

If the anomaly is visible on one flight line.-- As an ore-grate body greater than 200 feet in radius would be visible on two lines and as any finite source of radius smaller than 275 feet can be considered an elementary source, application of expression (1) yields the grade-area. If the anomaly is visible on two lines.--Two cases are possible, namely:

If the anomalies on two adjacent lines are approximately equal, it is a slab source. Compute $H_{S}(500,0, a)$ from the relation, $H_{S}(500,0, a)=$ $H \sec \theta$. The angle, $\theta$, is determined from the relative displacement of the peaks on the two adjacent lines. Then from figure 21 and from the computed $\mathrm{H}_{\mathrm{S}}\left(500_{2} \mathrm{O}, \mathrm{a}\right) / \mathrm{I}_{2}$ determine ${ }^{\prime} \mathrm{a}$. From expression (8) of Appendix I with ' $y$ ' set equal to zero and the measured $I$, determine grade-width and thence, the grade。 
If the anomalies are not equal in amplitude, it is a finite source. Let subscripts 1 and 2 denote two adjacent flight Iines with the highest peaks, and $I_{1}>I_{2}$. Then with $H_{1} / I_{1}$ as ordinate and $H_{2} / I_{2}$ as abscissa, determine ${ }^{\prime}$ from figure 20 . Compute $S A$ on Iines 1 and 2 and average the results. Multiply the average by the factor in table 12 corresponding to the proper ' $a$ '. The result is the grade-area from which grade can be obtained.

\section{CONCLUSIONS}

The method of interpretation proposed is based on a semi-empirical approach, wherein an assumed form of the radiation intensity law is used which fits both the experimental data and the analytical structure suggested by theory。

Certain general concepts underlying the semi-empirical approach to airborne radioactivity surveying warrant attention. These are:

Use of an elementary source of infinite thickness instead of the classical "point" source. In calculating the intensity of a theoretical point source located at an interface, it is necessary to take into account scattering and absorption at and near the interface. This is circumvented by observing the radiation intensity from an elementary source of infinite thickness, because the measurements themselves already contain the effects of both scattering and absorption. 
Use of elementary and infinitely thick broad behavior to determine the analytical form of the elementary source intensity expression。

The investigation, numerically and analytically, of the relationships between particular observable quantities and characteristics of sources selected to approximate natural sources。

The two observable quantities useful for determining grade-area relationships are the peak intensity and the area under the curve. The shape of the anomaly such as the breadth or slope at half maximum intensity, cannot be used for interpreting grade-area and (or) grade of natural sources although shape is useful in determining source type.

This particular method of utilizing the peak intensity and the area under the curve, for the interpretation of natural source characteristics is not unique. For example, once the source types have been identified the grade might be computed on the assumptions that the source is either directly below the detector ox at the point midway between two adjacent flight lines, yielding the two extreme values of grade. 
Based on investigation, numerical and analytical, of the relationships among the observable quantities and natural source characteristics, the following sequence is established for interpretation of actual anomalies:

Identification of one of four source types--the elementary (point), the finite (circular), the slab (Iine), and the broad (semi-infinite) source-- by appearance of an anomaly, either on one or on two or more adjacent flight lines, by the relative magnitudes of the anomaly on adjacent flight lines, or by flattening of the peak of the anomaly.

Use of grade-independent observables to determine source size. Determination of grade (grade-area and grade-breadth) of sources without reference to the (unknown) distance from source to detector.

The following results have been established for the conditions of surveying currently used by the U. S. Geological Survey:

Broad sources are finite sources which are greater than 850 feet in radius and slab sources which are greater than 1200 feet in width.

Elementary sources are finite sources less than 275 feet in radius.

Line sources are slab sources less than 800 feet in width. Line and slab sources greater than 1,700 feet in length are infinite in length. 
In application of expression (4), the total fractional error in the determination of the grade-area, $\frac{\delta(S A)}{S A}$. is related to the errors in $\mathrm{H}$ and $\mathrm{I}$ by

$$
\left|\frac{\delta(\mathrm{SA})}{\mathrm{SA}}\right| \leqslant 4: 73 \frac{\delta \mathrm{H}}{\mathrm{H}}+3.73 \frac{\delta I}{I}-8.46 \mathrm{~b}
$$

where ${ }^{\prime} b$ ' is the fractional error in measurement assumed to be the same for both $\mathrm{H}$ and I. Thus, in order to obtain the grade-area within a factor of two, the error in measurement must be less than 12 percent. Moreover, to obtain the grade within a factor of two, the sum of the fractional error in grade-area and twice the fractional error in ' $a$ ' must be less than 1. Particularly, in the case of overlapping anomalies, the uncertainty of resolving a compound anomaly into component anomalies will introduce very large errors in both $\mathrm{H}$ and I for the component anomalies.

The method of interpretation of the grade of broad sources is highly accurate as shown by numerous field investigations (R. M. Moxham, oral communication). Interpretation of the grade-width and grade of slab or line sources is also satisfactory. Finite and elementary sources, particularly those visible on only one flight line, are difficult to interpret; insufficient data are available to evaluate the accuracy of interpretation. 


\section{IITERATURE CITED}

Watson, G。 No, 1948, A treatise on the theory of Bessel functions (second edition): Cambridge University Press。 


\section{APPENDIX I。 \\ INTENSITY FROM SELECTED SOURCES}

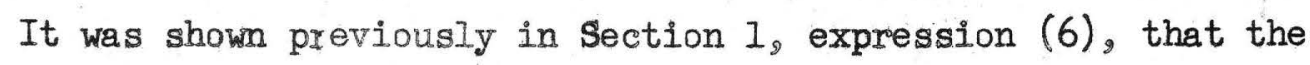
intensity from an elementary source is

$$
\begin{aligned}
& I_{p}\left(x_{2} P_{, a}\right)=\frac{\operatorname{cs} A}{S_{0} A} \frac{x}{r^{3}} e^{-\mu_{0} r}\left(I+\mu_{0} r-\gamma\left(\mu_{0} r\right)^{2}\right) \\
& =\frac{\operatorname{CSA}}{S_{D} A_{0}} \times f_{1}(x)
\end{aligned}
$$

where

$$
\begin{aligned}
& S=\text { source grade in percent } \mathrm{eU} \\
& S_{0}=\text { source grade in percent } \mathrm{eU} \text { standard }=0.35 \text { percent } \\
& A=\text { area of source }=\pi \mathrm{a}^{2} \\
& A_{0}=\text { area of standard source }=1600 \mathrm{ft}^{2} \\
& r^{2}=x^{2}+P^{2} \\
& \mu_{0}=1.461 \times 10^{-3} \mathrm{ft}^{-1} \text { at sea level } \\
& \gamma=0.342 \\
& C=3.19 \times 10^{7}
\end{aligned}
$$

and from a broad source is

$$
I_{b}(x)=\frac{2 \pi C S}{S_{0} A} e^{-\mu_{0} x}\left(I-\gamma \mu_{0} x\right)
$$

we rewrite

$$
f_{1}(r)=\sqrt{\frac{2}{\pi r}} \int_{\mu_{0}}^{\infty} \mathrm{pk}_{1 / 2}(\mathrm{pr}) \mathrm{p}^{1 / 2} \mathrm{dp}-\gamma_{\mu_{0}}^{2} \sqrt{\frac{2 \mu_{0}}{\pi r}} K_{1 / 2}\left(\mu_{0} r\right)
$$


where $\mathbb{K}_{I / 2}$ is modified Bessel function of the second kind, order $1 / 2$.

The line source intensity is

$$
I_{1}\left(x_{2} y_{2} a\right)=\frac{C S}{S_{0} A_{D}} a \times \int_{\infty}^{\infty} d z f(R)=\frac{2 C S}{S_{0} A_{D}} a x f_{2}(\omega)
$$

where $R^{2}=x^{2}+y^{2}+z^{2}$

$$
=x^{2}+y^{2}
$$

It is known (Watgon 1948) that

$$
\begin{aligned}
& \int_{0}^{\infty} K\left[p \sqrt{t^{2}+z^{2}}\right]\left[t^{2}+z^{2}\right]^{-\frac{r}{z}} d z=\sqrt{\frac{\pi}{2 p}} K_{r-1 / 2}(p t) t^{1 / 2-r} \\
& \therefore f_{2}(r)=\int_{0}^{\infty} f_{1}(R) d z=\int_{\mu_{0}}^{\infty} p K_{0}(p \omega) d p-\mu_{0} K_{0}\left(\mu_{0} \omega\right) \\
&=\mu_{p}^{2}\left[\frac{K_{1}\left(\mu_{0} \omega\right)}{\left(\mu_{0} \omega\right)}-K_{0}\left(\mu_{0} \omega\right)\right] \\
& \therefore I_{1}\left(x_{0} y_{0} a\right)=\frac{20 s}{s_{0} A} \mu_{0}^{2} a x\left[\frac{K\left(\mu_{0} \omega\right)}{\mu_{0} \omega}-\gamma K_{0}\left(\mu_{0} \omega\right)\right.
\end{aligned}
$$

The slab source intensity is

$$
\begin{aligned}
I_{8}\left(x, y_{9} a\right) & =\frac{2 C S}{S_{0} A} \mu_{0}^{2} x \int_{-d / 2}^{a / 2}\left[\frac{K_{1}\left(\mu_{0} R\right)}{\mu_{0} R}-\gamma K_{0}\left(\mu_{0} R\right)\right] d z \\
& =\frac{2 C S}{S_{0} A_{0}} \mu_{0} x G_{1}\left(x_{9} y_{9} a\right)
\end{aligned}
$$

where $R^{2}=x^{2}+(y-z)^{2}$.

$G_{1}(500, y, a)$ is tabulated in Table I.

The finite source intensity is

$$
\begin{aligned}
I_{f}(x, a) & =\frac{2 C S}{S_{0} A_{0}} x \int^{\beta} d \xi f_{1}(R) y d y \\
& =\frac{2 G S}{S_{0} A_{0}} \mu_{0} x G_{3}\left(x_{2} \rho, a\right)
\end{aligned}
$$


where

$$
\mathrm{R}^{2}=\mathrm{x}^{2}+\rho^{2}-2 \rho \mathrm{y} \cos \tau^{2}+\mathrm{y}^{2}
$$

$\mathrm{G}_{3}(500, \rho, a)$ is tabulated in Table III.

\section{APPENDIX II.}

AREA UNDER COUNTING RATE-METER CURVE

The response, $R(t)$, of a counting rate-meter of response time at time $t$ to a time dependent signal $I(t)$ is

$$
R(t)=\frac{1}{\tau} \int_{-\infty}^{t} e^{-\frac{\left(t-t^{r}\right)}{\tau}} I\left(t^{r}\right) d t^{r}
$$

Then the area under curve, $\mathrm{H}_{9}$ is

$$
H \equiv \int_{-\infty}^{+\infty} R(t) d t=\int_{-\infty}^{\infty} I\left(t^{\prime}\right) d t^{\prime}
$$

For the elementary source

$$
\begin{aligned}
H_{p}(x, z, a) & =\int_{-\infty}^{\infty} I_{p}\left(x, \sqrt{z^{2}+v^{2} t^{2}}, a\right) d t \\
& =\frac{2 C S A}{S_{0} A} x \int_{0}^{\infty} f_{I}(R) d t^{r} \\
& =\frac{2 C S A}{S_{0} A_{0}}\left(\frac{\mu_{0}^{2} x}{v}\right)\left[\frac{k_{1}\left(\mu_{0} s\right)}{\mu_{0} s}-K_{0}\left(\mu_{0} s\right)\right]
\end{aligned}
$$

where $s^{2}=x^{2}+z^{2}$ and $v$ is the velocity of the detector.

For the line source

$$
\begin{aligned}
\mathrm{H}_{f}\left(\mathrm{x}_{0} \theta, \mathrm{a}\right) & =\int_{-\infty}^{\infty} I_{e}(\mathrm{z}, \mathrm{vt} \cos \theta, \mathrm{a}) \mathrm{dt} \\
& =\underset{\mathrm{S}_{0} \mathrm{~A}}{\mathrm{SCS}} \mu_{0}^{2} \mathrm{ax} \int_{0}^{\infty}\left[\frac{\mathrm{K}_{I}\left(\mu_{0} R\right)}{\mu_{0} R}-K_{0}\left(\mu_{0} R\right)\right] d t^{\prime}
\end{aligned}
$$


where $R^{2}=x^{2}+v^{2} t^{2} \cos ^{2} \theta$ o Thus

$$
\begin{aligned}
H_{A}(x, \theta, a) & =\frac{2 \pi C S}{S_{0} A_{0}}\left(\frac{a}{v \cos \theta}\right) e^{-\mu_{0} x}\left(1-\gamma_{0} x\right) \\
& =\frac{4 C S}{S_{0} A_{0}}\left(\mu_{0} x\right) G_{2}(x, \theta, a)
\end{aligned}
$$

For the slab source

$$
\begin{aligned}
H_{S}(x, \theta, a) & =\int_{-\infty}^{+\infty} I_{S}\left(x_{\theta} \text { vt' } \cos \theta, a\right) d t^{\prime} \\
& =\frac{4 C S}{S_{0} A_{0}}\left(\mu_{0} x\right) G_{2}(x, \theta, a)
\end{aligned}
$$

identical to the line source.

For the finite source

$$
\begin{aligned}
H_{f}(x, z, a) & =\int_{-\infty}^{+\infty} I_{f}\left(x, \sqrt{z^{2}+v^{2} t^{2}}, a\right) d t^{r} \\
& =\frac{4 C S}{S_{0} A}\left(\mu_{0} x\right) G_{4}(x, z, a)
\end{aligned}
$$

The function $G(500, z, a)$ is tabulated in Table 9 